\title{
Downregulation of the essential Rrp44 ribonuclease causes extensive ultra-structure cell modifications in Trypanosoma brucei
}

Short title: Ultrastructure alterations in T. brucei Rrp44 knockdown cells

\section{Authors:}

Giovanna Cesaro ${ }^{\llbracket 1,2}$, Priscila M. Hiraiwa ${ }^{\llbracket 1}$, Flavia R. G. Carneiro³, Valérie Rouam ${ }^{4}$, Pierre Legrand ${ }^{5}$, José Javier Conesa ${ }^{6}$, Maurilio J. Soares ${ }^{1}$, Matthieu Réfrégiers ${ }^{4}$, Eva Pereiro $^{5}$, Beatriz G. Guimarães ${ }^{1,2}$, Frédéric Jamme ${ }^{4 *}$, Nilson I. T. Zanchin ${ }^{1 *}$.

IThese authors contributed equally to this work

${ }^{1}$ Carlos Chagas Institute, Oswaldo Cruz Foundation, Curitiba-PR, Brazil.

²Biochemistry Postgraduate Program, Federal University of Paraná, Curitiba, Brazil. ${ }^{3}$ Center for Technology Development in Healthcare, Oswaldo Cruz Foundation, Rio de Janeiro-RJ, Brazil.

${ }^{4}$ DISCO beamline, Synchrotron SOLEIL, Gif sur Yvette Cedex, France. ${ }^{5}$ PROXIMA I beamline, Synchrotron SOLEIL, Gif sur Yvette Cedex, France. ${ }^{6}$ MISTRAL beamline, ALBA Synchrotron Light Source, Barcelona, Spain.

${ }^{*}$ Co-corresponding authors

e-mail: nilson.zanchin@fiocruz.br (NITZ)

e-mail: frederic.jamme@synchrotron-soleil.fr (FJ) 


\section{Abstract}

Rrp44 is a conserved eukaryotic protein showing endonuclease and exoribonuclease activity that plays essential functions in RNA maturation and degradation. In Trypanosoma brucei, depletion of Rrp44 (TbRrp44) blocks processing of large subunit ribosomal RNA precursors, leading to disruption of ribosome synthesis and inhibition of cell proliferation. We used a combination of molecular and chemical markers to investigate the fate of $T$. brucei cells upon knockdown of TbRrp44. In addition, synchrotron deep UV microscopy and cryo soft X-ray tomography were used to investigate cell morphology and ultra-structure modifications. Downregulation of TbRrp44 results in induction of autophagy, inactivation of mitochondria and expansion of acidic and lysosome-derived vacuoles in parallel with enlargement of cell size. Nuclei also increase in size without changes in DNA content. 3D tomographic reconstructions revealed extreme vacuolation of the cytoplasm of TbRrp44 knockdown cells and general alteration of organelles. Calcium-containing vesicles (acidocalcisomes) were identified by Xray absorption near-edge structure spectra (XANES) of calcium $L_{2,3}$ edges on fully hydrated cells. The volumes of acidocalcisomes and lipid droplet were quantified from 3D reconstructions. Both were found in higher number and with larger volumes in TbRrp44 knockdown cells. These multiple defects indicate that a combination of signals, starting from nucleolar stress and activation of autophagy, converge to induce lysosome expansion. With time, the cytoplasm is taken up by lysosome-derived vacuoles, which may be one of the final stages leading to cell death triggered by TbRrp44 depletion. These studies provide the first evidence on the ultra-structure cell modifications caused by Rrp44 ribonuclease deficiency.

\section{Author summary}

Trypanosoma brucei is a parasitic protozoan belonging to the Kinetoplastidae Class, which displays distinct cellular, genomic and molecular features. These features include extra intervening sequences in the large subunit ribosomal RNA ( $r R N A)$ precursor that are not found in the homologous rRNA precursor of host cells. Genetic downregulation of the T. brucei Rrp44 (TbRrp44) ribonuclease shows that it is required for accurate excision of these intervening sequences to produce mature rRNA molecules. Here, we have used a multidisciplinary approach based on molecular and chemical markers, synchrotron deep UV microscopy and cryo soft X-ray tomography to show that downregulation of TbRrp44 leads to a series of cellular alterations that eventually result in cell death. Mitochondrial activity is particularly affected in parallel with induction of autophagy response, increase in size of the cell and of organelles such as acidocalcisomes and lipid droplets, and with a massive expansion of lysosome-derived vacuoles. The ultrastructural modifications that take place in $T$. brucei cells are nicely highlighted in the 3D reconstructions generated using cryo soft X-ray tomography images. This study provides new insights into the multiple cellular consequences of Rrp44 ribonuclease depletion in T. brucei parasites. 
bioRxiv preprint doi: https://doi.org/10.1101/2020.02.29.971424; this version posted February 29, 2020. The copyright holder for this preprint (which was not certified by peer review) is the author/funder, who has granted bioRxiv a license to display the preprint in perpetuity. It is made available under aCC-BY-NC-ND 4.0 International license.

\section{Introduction}

Trypanosoma brucei is the causative agent of human African trypanosomiasis. It belongs to a group of pathogenic trypanosomatids well known for the highly complex diseases that they cause, which also includes the various types of leishmaniasis and Chagas disease. This group is also known for presenting unique cellular and molecular features. One of such features is the presence of a single giant mitochondrion containing a special part, the kinetoplast, which accumulates a large mass of mitochondrial DNA (kDNA). Their genome organization is also peculiar. Protein-coding genes are organized into long polycistronic units without canonical RNA polymerase II promoters. These polycistronic units are constitutively transcribed and monocistronic mRNAs are generated by trans-splicing and polyadenylation $[1,2]$. Trypanosomatid ribosomes contain trypanosomatid-specific rRNA expansions [3,4] with implications in the internal structure arrangement and possibly also in ribosome activity. The structure of the rRNA genes present differences as well. The segment encoding the molecule corresponding to the $28 \mathrm{~S}$ rRNA of other eukaryotes is separated by spacer sequences into six fragments in $T$. brucei and $T$. cruzi and in seven fragments in Leishmania species (reviewed in [5]).

The molecular and biochemical differences between trypanosomatids and host cells is the major motivation of our work, which aims to identify and refine the description of trypanosomatid-specific mechanisms that could reveal new targets for development of inhibitors against this group of parasites. The presence of seven/eight spacer sequences in the rRNA precursor, rather than the two usually present in eukaryotes, anticipates differences in the rRNA maturation process in trypanosomatids, either regarding the enzymes involved in the process and/or their biochemical specificities. In this context, we are investigating the Trypanosoma brucei Rrp44 homologue (TbRrp44). Rrp44 is a conserved protein showing a modular domain arrangement containing an endonuclease PIN domain (PilT N-terminal domain) in the N-terminal portion, followed by two cold shock domains (CSD1 and CSD2), an exoribonuclease catalytic domain (RNB) and an S1 domain in the C-terminus [6,7]. Most of the information on the molecular and biochemical functions of Rrp44 was generated from studies carried out in Saccharomyces cerevisiae. As part of the exosome complex, Rrp44 participates in processing of rRNA, small nucleolar (snoRNA), small nuclear (snRNA) RNAs [8,9] and in quality control of RNA maturation [10,11]. Conservation of Rrp44 function across eukaryotic species is supported by the findings that both the human and plant orthologues complement $S$. cerevisiae RRP44 gene deletion [12,13].

Different phenotypes have been described for mutations or knockdown of Rrp44 orthologous genes from different organisms. The first report on a Rrp44 orthologue describes a dis3 cold-sensitive mutant of the fission yeast Schizosaccharomyces pombe, which did not accomplish mitotic chromosomes separation during cell division [14]. The S. pombe dis $3^{+}$gene was subsequently shown to encode an essential $110 \mathrm{kDa}$ protein involved in mitotic control [15], kinetochore formation and kinetochore-microtubule interactions [16]. Parallel studies on the RNA exosome complex revealed that the protein Rrp44 (after ribosomal RNA processing) was the dis3 orthologue from the budding yeast $S$. cerevisiae [17-19]. Interestingly, a recent study has shown that mutations in the exonuclease domain of Rrp44 leads to genome instability in $S$. cerevisiae [20], which is consistent with the cellular phenotypes described for $S$. pombe mutants of dis3. Currently, Uniprot (https://www.uniprot.org) recommends the name DIS3 to designate the gene and Rrp44 to designate the protein encoded by the DIS3 gene. In multicellular organisms, Rrp44 function is required for a balance between promotion of 
embryogenesis and development and control of cell proliferation. Knockdown of Rrp44 orthologues was shown to inhibit female gametophyte development and early embryogenesis in Arabidopsis thaliana [13,21], to cause growth reduction and larval lethality in Drosophila melanogaster [22] and early stage larval death in Caenorhabditis elegans [23]. D. melanogaster cells depleted of Rrp44 also show delayed mitosis, aneuploidy and overcondensed chromosomes [23]. Loss of control of cell proliferation connected to reduced Rrp44 activity has been reported to mammalian cell lineages, mice, D. melanogaster and Caenorhabditis elegans [22-24]. In humans, deep sequencing and genetic mapping have found DIS3 among the most frequently mutated genes in multiple myeloma patients [25,26], a finding that is consistent with a role for Rrp44 on control of cell proliferation in multicellular organisms.

Previous studies have shown that Rrp44 is essential for Trypanosoma brucei viability [27]. As observed for the yeast and human Rrp44, T. brucei Rrp44 (TbRrp44) is required for maturation of the 3'-end of the 5.8S rRNA [27]. However, it did not co-purify with other exosome complex components [28]. As proposed in a recent work by our own group, this lack of association to the exosome complex may be due to amino acid substitutions in the PIN domain of TbRrp44 together with the presence of a C-terminal extension in the exosome core subunit TbRrp42 [29]. We have also previously shown that, in addition to 5.8S rRNA processing, TbRrp44 is also required for maturation of the complete large ribosomal subunit rRNA precursor [29]. This finding connects TbRrp44 with still unknown processing steps involved in the excision of the additional internal spacer sequences of the rRNA precursor.

In the course of the same study, we have observed that knockdown of TbRrp44 causes extremely drastic effects on $T$. brucei cells, which have not been described previously. Therefore, in the present work, we have investigated the cellular alterations that take place in the course of TbRrp44 depletion. A set of different analyses using cryo soft X-ray tomography (cryo-SXT) and fluorescence imaging methods was employed to investigate these phenotype switches. Biochemical and molecular markers provided information on the organelles that are affected. We show that depletion of TbRrp44 blocks cell proliferation in parallel with general changes in the cytoplasm. 3D reconstructions revealed an extreme increase in the size of vacuoles and a general enlargement of various types of cellular vesicles. This work reveals unprecedented details of the cellular changes that take place in $T$. brucei cells in a route to death after depletion of an essential protein. 
bioRxiv preprint doi: https://doi.org/10.1101/2020.02.29.971424; this version posted February 29, 2020. The copyright holder for this preprint (which was not certified by peer review) is the author/funder, who has granted bioRxiv a license to display the preprint in perpetuity. It is made available under aCC-BY-NC-ND 4.0 International license.

\section{Results}

\section{TbRrp44 knockdown activates autophagy response}

As shown in previous studies [27,29], knockdown of TbRrp44 impairs large ribosomal subunit RNA maturation, causing accumulation of unprocessed pre-rRNA in the nucleolus and disrupting ribosome synthesis. In animal cells, similar defects caused by mutation or deficiency in genes encoding ribosomal proteins and ribosome synthesis factors, result in nucleolar stress leading to activation of autophagy, cycle arrest and/or apoptosis [30,31]. Autophagy starts with formation of autophagosomes, which are dense double membrane structures that later fuse with lysosomes forming autophagolysosomes [32,33]. Autophagosomes can easily be visualized by fluorescence microscopy using specific autophagy markers. To test whether TbRrp44 depletion activates autophagy, we transformed cells from the TbRrp44 conditional strain with the autophagy marker ATG8.2 fused to the yellow fluorescent protein [34]. Autophagy induction in procyclic $T$. brucei cells can be achieved by a two-hour incubation under amino acid deprivation. In TbRrp44 knockdown cells incubated in medium, both the ratio of autophagosomes per cell and the percentage of cells presenting autophagosomes are similar to the control cells maintained under amino acid deprivation (Fig 1). This result shows that TbRrp44 depletion induces the autophagy response. The TbRrp44 knockdown cells are more sensitive to autophagy induction since both the ratio of autophagosomes per cell (Fig 1B) and the ratio of cells presenting autophagosomes (Fig 1C) increase when they are incubated under amino acid starvation. These results demonstrate that autophagy participates in the events that lead to inhibition of proliferation of TbRrp44-depleted cells.

\section{Changes in DNA content and cellular membrane integrity in TbRrp44 knockdown cells}

Downregulation of TbRrp44 by RNA interference blocks cell proliferation ([29] and S1 Fig). The number of cells in the knockdown cultures remains nearly unchanged starting at 48 hours after RNAi induction. Flow cytometry analysis based on DNA content, however, revealed relatively small changes in the cell cycle up to the time point of $72 \mathrm{~h}$ of knockdown (Fig 2A). These includes a small increase of the G1 population, in parallel with a reduction of the cell population in the $S$ and G2/M phases (Fig 2B). Stronger alterations in DNA content were detected at $96 \mathrm{~h}$ after knockdown when an increase of the sub-G1 population and a reduction of all other stages are observed ( 30\%) (Fig 2A and $2 \mathrm{~B})$. The sub-G1 population comprises cells that are undergoing DNA damage. Low molecular weight DNA fragments are not retained during the fixation process [35] causing a reduction in the DNA content after long TbRrp44 depletion times.

In trypanosomatids, replication of the kinetoplast $(\mathrm{K})$ and nuclear $(\mathrm{N})$ DNA is only partially overlapping. According to previous studies on nuclear/kinetoplast ratio, $1 \mathrm{~N} / 1 \mathrm{~K}$ cells comprise the $\mathrm{G} 1$ and $\mathrm{S}$ phases, $1 \mathrm{~N} / 2 \mathrm{~K}$ cells are in $\mathrm{G} 2$ and $2 \mathrm{~N} / 2 \mathrm{~K}$ cells are mitotic or postmitotic phases $[36,37]$. We have analyzed the N/K ratio of TbRrp44 knockdown cells using a high content imaging system, which allowed for automated segmentation of kinetoplasts and nuclei. Quantification of over one thousand cells per treatment revealed that the N/K ratio is consistent with the results obtained by flow cytometry, with a slight increase of $1 \mathrm{~N} / 1 \mathrm{~K}$ cells and reduction of $1 \mathrm{~N} / 2 \mathrm{~K}$ cells observed for the knockdown strain. These differences are significant only for cells at $72 \mathrm{~h}$ of TbRrp44 depletion (Fig 2C). However, an important change detected in this cell involves the size of the nuclei. The image segmentation used to determine the number of nuclei per cell also allowed for determination of the nuclear area, which was 
bioRxiv preprint doi: https://doi.org/10.1101/2020.02.29.971424; this version posted February 29, 2020. The copyright holder for this preprint (which was not certified by peer review) is the author/funder, who has granted bioRxiv a license to display the preprint in perpetuity. It is made available under aCC-BY-NC-ND 4.0 International license.

increased by $\sim 10 \%$ and $\sim 20 \%$ at 48 and $72 \mathrm{~h}$ after TbRrp44 depletion, respectively (Fig 3D). Nuclear enlargement without increase in DNA content has been related to senescence in mammalian cells in response to treatments with excess thymidine [38] resveratrol, quercetin [39] and sirtuin inhibitors [40]. There is no similar phenotype reported for trypanosomatids, but nuclear enlargement may represent a senescence-like process in TbRrp44-depleted cells.

Loss of cell membrane asymmetry is one of the initial cellular pro-death signals. It is caused by externalization of phosphatidylserine residues, which under normal physiological conditions reside in the inner leaflet of the plasma membrane. We have evaluated the level of phosphatidylserine inversion by flow cytometry using annexin $\mathrm{V}$ conjugated with Alexa fluor 488 in parallel with propidium iodide, which is an indicator of membrane damage. The population of cells positive for annexin $\mathrm{V}$ was in the range of $20 \%$ for the 48,72 and $96 \mathrm{~h}$ time points. A fraction of $10 \%$ of the cell population, positive for both annexin $\mathrm{V}$ and propidium iodide, started to be detected at $72 \mathrm{~h}$ of knockdown (Fig 3). There is just a small percentage of cells only positive for propidium iodide, showing that they are not undergoing necrosis. Positive labeling for annexin $\mathrm{V}$ and positive labeling for both annexin $\mathrm{V}$ and propidium iodide have been regarded, respectively, as early and late stages of apoptosis in multicellular organisms. Trypanosomatids do not seem to have the same morphological markers neither the molecular players that regulate cell death by apoptosis in multicellular organisms. It has also been proposed that trypanosomatid cell death occurs either by necrosis or by incidental death (reviewed in [41]). Independently of the process type that is going on, propidium iodide and annexin $\mathrm{V}$ labeling indicated that the nuclear DNA and cell membrane remain relatively stable for a long time after TbRrp44 depletion.

\section{Alterations in autofluorescence and increase in cell size}

As described in previous studies, downregulation of TbRrp44 affects pre-rRNA processing, ribosome biogenesis and leads to inhibition of cell proliferation ([27,29], S1 Fig). Defective ribosome biogenesis is expected to cause reduction in protein synthesis leading to a reduction of total cell protein. In addition, drastic morphological changes start to appear upon TbRrp44 depletion (Fig 4A). Some cells become deformed and larger as a function of time of TbRrp44 knockdown. These defects led us to employ direct methods to determine biochemical and cellular changes that take place after TbRrp44 depletion. In order to evaluate total protein content, we measured the intrinsic fluorescence emission of tryptophan and tyrosine using the imaging facilities of Synchrotron SOLEIL's DISCO beamline. This facility has a tunable photon source in the 180-600 $\mathrm{nm}$ range, allowing for excitation of biological samples with deep ultraviolet radiation [42]. In these experiments, excitation wavelength was set at $275 \mathrm{~nm}$ and full field images from the same cells were acquired in the 307-323 nm, 327-353 and at 451$486 \mathrm{~nm}$ emission ranges, which allow for parallel quantification of tyrosine, tryptophan and $\mathrm{NAD}(\mathrm{P}) \mathrm{H}$ fluorescence, respectively.

The average of the integrated fluorescence intensity in the tryptophan contribution range $(327-353 \mathrm{~nm})$ increased with time by approximately $23 \%$ at $48 \mathrm{~h}, 39 \%$ at $72 \mathrm{~h}$ and $43 \%$ at 96 hours after TbRrp44 depletion (Fig 4B). Similarly, the integrated fluorescence intensity in the tyrosine contribution range $(307-323 \mathrm{~nm}$ ) increased from $\sim 25 \%$ to $36 \%$ in the time interval between 48 and $96 \mathrm{~h}$ of depletion (Fig $4 \mathrm{C}$ ). This was an intriguing finding, since we expected a decrease of fluorescence for these ranges in TbRrp44 knockdown cells. An analysis of protein content in cell extracts does not indicate a higher protein content in TbRrp44-depleted cells (S1 Fig). Interestingly, when we examined the area of the cells used to quantify the 
bioRxiv preprint doi: https://doi.org/10.1101/2020.02.29.971424; this version posted February 29, 2020. The copyright holder for this preprint (which was not certified by peer review) is the author/funder, who has granted bioRxiv a license to display the preprint in perpetuity. It is made available under aCC-BY-NC-ND 4.0 International license.

fluorescence, we observed that during the course of TbRrp44 depletion, the cells showed an increase in the cell area, indicating an increase in cell size (Fig 4B, C and D). The area of TbRrp44 knockdown cells is $25-30 \%(p<0.0001)$ larger than the area of control cells. It is important to note that as consequence of a larger cell size, the ratio between the value of integrated fluorescence intensity average and cell area average, results in values that are statistically different only for tryptophan fluorescence at $96 \mathrm{~h}$ after TbRrp44 depletion $(\mathrm{p}=$ 0.0022) (Fig 4B).

In addition to the protein chromophores, we applied direct measurement methods to determine the energy metabolite co-factors $\mathrm{NAD}(\mathrm{P}) \mathrm{H}$ and FAD. Nicotinamide adenine dinucleotide (NAD) is a cofactor that shifts between oxidized $\left(N A D^{+}\right)$and reduced (NADH) forms and plays a central role in energy metabolism [43]. Its phosphorylated form (NADPH) participates mainly in anabolic reactions, including synthesis of fatty acids and steroids. Their reduced states (NADH and NADPH) display identical excitation and emission fluorescence spectra [44]. Here, they are referred to as $N A D(P) H$ since they cannot be distinguished. Both exist as free and enzyme-bound forms, which may alter their fluorescence patterns. Although $\mathrm{NAD}(\mathrm{P}) \mathrm{H}$ has two excitation maxima at $260 \mathrm{~nm}$ and $345 \mathrm{~nm}$, in this work $\mathrm{NAD}(\mathrm{P}) \mathrm{H}$ was excited at $275 \mathrm{~nm}$ to use the range of maximum flux of the DISCO beamline. The integrated fluorescence intensity in the $\mathrm{NAD}(\mathrm{P}) \mathrm{H}$ contribution range $(451-486 \mathrm{~nm})$ showed an increase of approximately $21 \%$ at 48 h, $30 \%$ at $72 \mathrm{~h}$ and $41 \%$ at 96 hours after TbRrp44 depletion (Fig $4 \mathrm{D})$. Autofluorescence was distributed in the whole cell (S2 Fig), suggesting similar NAD(P)H levels in all cell compartments. Cell area average was also significantly increased, when estimated based on the NAD(P)H fluorescence emission (Fig 4D). This result is consistent with the cell area quantification using tryptophan and tyrosine fluorescence. Similarly, the ratio between the value of integrated fluorescence intensity average divided by the cell area average for $\mathrm{NAD}(\mathrm{P}) \mathrm{H}$ emission resulted in difference values that are not significant between both cell treatments (Fig 4D). This result indicates that there are no significant changes in the content of $\mathrm{NAD}(\mathrm{P}) \mathrm{H}$ in TbRrp44-depleted cells.

Flavin adenine dinucleotide (FAD) and its reduced form $\mathrm{FADH}_{2}$ are involved in catabolic reactions, electron transport chain and energy metabolism, but only FAD presents autofluorescence. In addition, FAD exists mostly as a cofactor bound to enzymes involved in redox reactions $[45,46]$. Along with proteins and $N A D(P) H$, investigation of autofluorescence in the FAD contribution range is particularly interesting for our analyses aiming to determine cellular changes by direct methods. It has been previously described that cells from the trypanosomatid species Leishmania tarantolae display significant autofluorescence with excitation at 450-500 $\mathrm{nm}$ and emission peaks at 458/538 nm [47]. The major contributor for fluorescence in this range is FAD. Excitation/emission in 460-500 nm/512-542 nm was determined for control and cells depleted of TbRrp44 for $72 \mathrm{~h}$. As expected, T. bruceicells also showed a relatively strong autofluorescence. In control cells, the fluorescence signal was typical of trypanosomatid single giant mitochondrion [48] distributed along the cell membrane with a dark central area, which is occupied by the nucleus and adjacent structures. T. brucei cells showed also a structure with strong fluorescence (Fig 4E) that was not seen in Leishmania tarantolae cells [47]. Surprisingly, the TbRrp44 knockdown cells presented stronger fluorescence intensity average, which was approximately $50 \%$ higher than control cells (Fig 4E). As observed in previous experiments, TbRrp44 knockdown cells showed a larger cell area average $\left(32.9 \mu \mathrm{m}^{2}\right)$ relative to control cells $\left(25.6 \mu \mathrm{m}^{2}\right)(\mathrm{p}<0.0001)$ (Fig $\left.4 \mathrm{E}\right)$. In the $F A D$ emission range, the ratio between integrated fluorescence intensity average and the 
bioRxiv preprint doi: https://doi.org/10.1101/2020.02.29.971424; this version posted February 29, 2020. The copyright holder for this preprint (which was not certified by peer review) is the author/funder, who has granted bioRxiv a license to display the preprint in perpetuity. It is made available under aCC-BY-NC-ND 4.0 International license.

cell area was also higher for the knockdown cells ( $p<0.0001)$ (Fig 4E). The increase of the oxidized FAD form suggests that energy metabolism is affected in TbRrp44 knockdown cells.

\section{Mitochondrial activity is affected in TbRrp44 knockdown cells}

The increase of autofluorescence in the green range $(512-542 \mathrm{~nm})$ described above indicated mitochondrial alterations in TbRrp44 knockdown cells, which were further investigated by testing markers of mitochondrial activity and integrity. Currently, there are several organic dyes available that can be used for labelling of mitochondria with relatively high selectivity. In this work, we used MitoTracker Orange CMTMRos (Molecular Probes/ThermoFisher), which accumulates in mitochondria once added to the cell culture at low nanomolar concentrations. In active mitochondria, it undergoes oxidation and emits fluorescence (Fig 5A). As in all depletion experiments, TbRrp44 knockdown cells showed an increase in the cell area (control cells, $31.2 \mu \mathrm{m}^{2}$; knockdown cells, $37.6 \mu \mathrm{m}^{2} ; p<0.0001$ ) (Fig $5 \mathrm{~B})$. The fluorescence intensity average per cell area was two times lower in TbRrp44 knockdown cells ( $p<0.0001$ ) (Fig 5B). This decrease indicates reduction or loss of mitochondrial membrane potential affecting mitochondrial activity. This result is consistent with the autofluorescence analysis in the green range, which indicated alterations in the mitochondrial function of TbRrp44-depleted cells.

The structural integrity of mitochondria was evaluated using mtHsp40 tagged with the HA epitope as marker, which has previously been shown to localize in the mitochondria of $T$. brucei [49]. This analysis was carried out in the TbRrp44 conditional strain transfected with a linear DNA fragment encoding mtHsp40 containing the human influenza hemagglutinin epitope tag (HA-tag) in the C-terminal and the puromycin selection marker. The subcellular localization of the mtHsp40-HA protein was determined by immunolocalization. mtHsp40-HA showed similar subcellular distribution in both control and knockdown cells (Fig 5C and D). No mislocalization of mtHsp40-HA neither difference in fluorescence levels were observed. With this analysis, it was not possible to observe alterations in the mitochondrial structure. However, the increase of autofluorescence in the green range and the reduced MitoTracker fluorescence are indications that the mitochondria of TbRrp44 knockdown cells present reduced function.

\section{Acidic vacuoles increase in size and number in TbRrp44 knockdown cells}

The cellular alterations described for pharmacologically induced cell death in $T$. brucei include increase of lysosomal structures, fragmented nucleus, chromatin condensation and swollen mitochondrion [50-53]. In order to investigate the nature of the vesicles in cells depleted of TbRrp44, we performed analyses using the chemical marker LysoTracker. Despite its name suggesting that it would be specific for lysosomes, it stains all acidic vesicles in living cells, which in the case of $T$. brucei should include lysosomes and acidocalcisomes. However, the calcium analysis described below shows that acidocalcisomes are not the main contributors to the extreme vacuolation that takes place after depletion of TbRrp44. Interestingly, cells depleted of TbRrp44 showed very strong fluorescence upon staining with LysoTracker. The ratio of total fluorescence intensity per cell area revealed a six-fold difference between control and knockdown cells (Fig 6A and B). In addition, the LysoTracker-stained vacuoles are much larger in TbRrp44 knockdown cells. These results are consistent with the hypothesis that the vacuoles that increase in size and number originate from lysosomes.

Electron microscopy images of TbRrp44 knockdown cells revealed the presence of large vacuoles, which are not seen in control cells (Fig 6C). However, no dense multilamellar 
bioRxiv preprint doi: https://doi.org/10.1101/2020.02.29.971424; this version posted February 29, 2020. The copyright holder for this preprint (which was not certified by peer review) is the author/funder, who has granted bioRxiv a license to display the preprint in perpetuity. It is made available under aCC-BY-NC-ND 4.0 International license.

membrane structures neither the structural alterations previously described taking place during pharmacologically induced T. brucei cell death [50-53] was seen in TEM images of TbRrp44 knockdown cells.

\section{Increase of vesicles containing the lysosomal marker p67}

The hypothesis that the vesicles that increase in size and number originate from the lysosome was further supported by the data obtained from the analysis using the lysosomal/endosomal membrane protein p67 [54] as a marker. It was previously shown to localize in T. bruceilysosomes in fusion with both the yellow fluorescent protein (YFP) [55] and the influenza hemagglutinin (HA) epitope tag [56]. The subcellular localization of p67 was evaluated in the TbRrp44 conditional strain, which was transfected separately with linear DNA fragments encoding p67 fused to either the influenza HA tag or the green fluorescent protein in the C-terminal and the puromycin selection marker. Fluorescence microscopy analysis revealed a higher number of fluorescent vacuoles for p67 with both markers. The subcellular localization of p67-GFP was analyzed in living cells. Total p67-GFP fluorescence was significantly increased in TbRrp44 knockdown cells. However, as the knockdown cells present a larger cell area average (control cells, $33.7 \mu \mathrm{m}^{2}$; knockdown cells, $37 \mu \mathrm{m}^{2} ; \mathrm{p}=0.0159$ ), the difference of GFP fluorescence intensity per cell area between control and knockdown cells was not significant (Fig 7A and B). Immunolocalization of p67-HA using an anti-HA antibody, on the other hand, revealed a significant increase of p67-positive vacuoles in the quantification of total fluorescence and also for the ratio between the fluorescence intensity and the cell area, even though TbRrp44 knockdown cells presented a larger size in these quantifications (control cells, $23 \mu \mathrm{m}^{2}$; knockdown cells, $28 \mu \mathrm{m}^{2} ; \mathrm{p}=0.0001$ ) (Fig $7 \mathrm{C}$ and $\mathrm{D}$ ). This result corroborates the hypothesis that the large vesicles should be derived from lysosomes.

\section{D reconstruction of the cellular ultrastructure by cryo soft X-ray tomography}

To better evaluate the ultrastructural alterations that take place in cells depleted of TbRrp44, we used cryo soft X-ray tomography (cryo-SXT), which allows reconstitution of the $3 \mathrm{D}$ structure of whole close-to-native cells at nanometer-resolution $[57,58]$. Cryo-SXT is usually performed with vitrified samples in the native state. However, preparation of grids with $T$. brucei cells was not so straightforward. Due to flagellar activity, the living T. brucei procyclic form is fast moving and does not adhere well to poly-lysine treated grids. TbRrp44 knockdown cells, by their turn, appeared to be very fragile as they "compressed" during grid preparation, assuming a flat conformation (S3 Fig). Both problems were overcome by a quick fixation step with $2 \%$ paraformaldehyde (PFA) (3 min incubation and 5 min centrifugation). This treatment blocked the flagellar movement of the wild-type cells and avoided deformation of the TbRrp44 knockdown cells, allowing preparation of grids with cells evenly distributed without apparent deformations (S3 Fig).

Analysis of reconstructed 3D slices revealed heterogeneities in the structural changes among different TbRrp44 knockdown cells (Fig 8 and S4 and S5 Figs). Some cells showed a wider and shorter conformation while others were elongated and thinner. Major organelles including mitochondrion, nucleus, nucleolus, flagellar pocket, kinetoplast, lipid droplets and other strong absorbing vacuoles showed regular conformation in control cells (Fig 8). TbRrp44 knockdown cells, on the other hand, showed extreme vacuolation of the cytoplasm and enlargement of all type of vesicles. The nuclei and nucleoli became larger and the flagellar pocket appears compressed (Fig 8). In knockdown cells, heterogeneities are observed both in 
bioRxiv preprint doi: https://doi.org/10.1101/2020.02.29.971424; this version posted February 29, 2020. The copyright holder for this preprint (which was not certified by peer review) is the author/funder, who has granted bioRxiv a license to display the preprint in perpetuity. It is made available under aCC-BY-NC-ND 4.0 International license.

the posterior and anterior poles of the cells. In the posterior pole, some cells showed low absorption vacuoles and deformed kinetoplast while others showed enlargement of vesicles with high absorbance (S5 Fig). Similarly, in the anterior pole, some cells showed a high number of large low absorbance vacuoles and others a high number of small vesicles with high absorption (S5 Fig).

Three-dimensional (3D) reconstruction of the cell structure and manual segmentation of the organelles surface shows control cells with nicely defined flagellum, kinetoplast, lipid droplets, a round flagellar pocket, a round nucleus and the nucleolus. The mitochondrial network is well organized along the two sides of the cell (Fig 9). On the other hand, the 3D reconstructions of TbRrp44 knockdown cells (Fig 9) present different degrees of vacuolation. In these cells, the most striking alteration is the presence of a large number of low-absorption vacuoles that occupy most of the cytoplasmic space and the displacement and disorganization of the mitochondrion. The low-absorption vacuoles should correspond to the vesicles stained with lysotracker and with the lysosomal marker p67, which are the ones showing the largest changes in TbRrp44-depleted cells. Figure 9 shows in the central panel a dividing cell with two kinetoplasts, a dividing flagellum, alterations in the mitochondrial network and presence of low absorption vacuoles in both cell poles. The cell in the right panel contains a single large vacuole taking most of the anterior pole and surrounding the nucleus. In most cells, the nuclear boundary is irregular, and the nucleolus shows a larger size than in control cells. In addition, most TbRrp44 knockdown cells show a higher number and larger lipid droplets (Fig 9). Quantifications of lipid droplets and acidocalcisomes are presented in the sections below.

\section{Acidocalcisomes present a larger size in TbRrp44 knockdown cells.}

Acidocalcisomes are lysosome-related organelles rich in calcium and other cations, containing also a high concentration of pyrophosphate (PPi) and polyphosphate (poly P). They possess proton pumps and transporters, playing a central role in calcium signaling and in phosphate and cation homeostasis [59,60]. To evaluate the extent of alteration in calciumcontaining organelles in $T$. brucei cells deficient for TbRrp44, we have used cryo spectromicroscopy at MISTRAL to obtain X-ray absorption near-edge structure spectra (XANES) on fully hydrated cells. Sequential images were acquired from the same field of view starting below the $\mathrm{Ca}_{2,3}$ absorption edge, up to $356 \mathrm{eV}$, which is above the $\mathrm{Ca}$ absorption edge [61,62] (Fig 10A). For localization of calcium-containing organelles, images were acquired at pre-edge and calcium L3-edge energies for several control and knockdown cells. Calcium was identified by the difference between the L3-edge and pre-edge images (Fig 10C). We assumed that the organelles presenting high calcium content correspond to the acidocalcisomes. The average volume of acidocalcisomes is approximately 5 times larger in TbRrp44 knockdown cells when compared with control cells (Fig 10B).

\section{TbRrp44 knockdown cells contain a higher number of lipid droplets showing a larger volume}

The analyses with soft X-rays in the calcium pre-absorption and absorption edges provided information that allowed to distinguish the acidocalcisomes from the vesicles showing the strongest absorption (Fig 11C). Those vesicles correspond to lipid droplets, which display a higher absorption than water rich organelles [63-66]. Lipids are essential components of cellular membranes and key components for energy storage and metabolism. Neutral lipids, such as fatty acids, are stored in lipid droplets, which are the major cellular reservoirs for this 
type of molecules. Lipid droplets also contain a specific set of proteins, such as enzymes involved in lipid synthesis, membrane trafficking and organelle transport. They also function in protection against the toxic effects of excess of free fatty acids (reviewed in [67,68]). Given the central role of these organelles for cell function and the interplay of fatty acids from lipid droplets with other organelles, we evaluated the content of lipid droplets in cells depleted of TbRrp44. Lipid droplets were quantified both from 3D cryo-SXT reconstructions and from images of cells stained with the fluorescent dye Nile Red acquired using a high-content imaging system, which allowed the analysis of a larger number of cells. The 3D-reconstructed knockdown cells showed an average of six lipid droplets per cell, while the average of control cells was approximately three (Fig 11 A and B). In addition, the lipid droplets in knockdown cells showed an average size two times larger than in control cells (Fig 11B). In the analysis using Nile Red, TbRrp44 knockdown cells show both a wider range of fluorescence signal intensity and a significant increase of fluorescence intensity average (Fig 11C and D). The difference between control and knockdown cells, however, is smaller relative to the quantifications of the lipid droplets of cryo-SXT 3D reconstructed cells. This is most probably due to the lower resolution of the fluorescence microscopy technique. Together, the lipid droplet quantifications show that lipid metabolism is highly affected by depletion of TbRrp44. 
bioRxiv preprint doi: https://doi.org/10.1101/2020.02.29.971424; this version posted February 29, 2020. The copyright holder for this preprint (which was not certified by peer review) is the author/funder, who has granted bioRxiv a license to display the preprint in perpetuity. It is made available under aCC-BY-NC-ND 4.0 International license.

\section{Discussion}

The experimental data available on the biochemical activity and molecular function of TbRrp44 homologues underlie the importance of these proteins for maturation of all types of RNA precursors and for removal of excised products and RNAs targeted for degradation [811]. The current working models that drive the studies on Rrp44 function are generally based on the investigation of its biochemical activity towards specific RNA targets. However, the consequences of Rrp44 genetic deficiency are more complex to understand. They include its requirement for sister chromatid separation and genome stability in yeast $[14-16,20]$ as well as the balance of its function in multicellular organisms where it is required not only for the progression of cell division and development [13,21-23], but also for control of cell proliferation $[23,24]$.

In trypanosomatids, which present a constitutive transcription of polycistronic premRNA units and extensively segmented ribosomal RNA, a higher requirement of RNase activity is expected for accurate processing of the precursors and degradation of the excised RNA segments. The few studies on TbRrp44 confirm its requirement for rRNA maturation and its essential function for proliferation [27,29]. In this work, we performed a series of analyses of TbRrp44 knockdown cells to fully investigate the cellular consequences of disruption of ribosome synthesis by TbRrp44 depletion. An early response to nucleolar stress caused by deficient ribosome synthesis is activation of autophagy [30,31]. Both the ratio of autophagosomes per cell and the percentage of cells presenting autophagosomes in TbRrp44depleted cells is consistent with previous reports on autophagy induction in T. brucei [34, 69, 70] and support the hypothesis that TbRrp44 depletion indeed activates autophagy response. Autophagy has already been linked to cell death in T. brucei [32] and may represent an important signal for mitochondrial inactivation, lysosome expansion and inhibition of cell proliferation in cell depleted of TbRrp44.

The time courses of TbRrp44 depletion show that the number of cells in the cultures does not change after the first $48 \mathrm{~h}$ of TbRRp44 depletion. However, the alterations related to DNA content seem to be quite mild for cells that are no longer dividing. DNA damage detected by appearance of the sub-G1 population starts to appear only at the $96 \mathrm{~h}$ after the induction of RNA interference, which corresponds to approximately three days after the cells stopped dividing. The defects involving cell membrane asymmetry and permeability are relatively mild. At $72 \mathrm{~h}$ after TbRrp44 depletion, only approximately $25 \%$ of the population shows positive labeling for annexin $\mathrm{V}$ and propidium iodide, which comprises the cells at early and late apoptosis stages. At $96 \mathrm{~h}$ after TbRrp44 depletion, this population rises to just $\sim 30 \%$. These are important differences as compared to the effect caused by spliced leader silencing $[71,72]$ and knockdown of the nuclear RNA-binding protein TbRRM1 [37], both leading to a strong increase of the hypodiploid sub-G1 population associated to apoptosis-like cell death processes as indicated by the high levels of annexin $\mathrm{V}$ and propidium iodide staining.

As depletion of TbRrp44 does not lead to increase in DNA content, the finding that these cells contained nuclei with larger size was intriguing. Similar events have been reported for mammalian cells undergoing senescence [38-40]. To the best of our knowledge, such a process has not been described for trypanosomatids yet, but it is well known for the budding yeast $S$. cerevisiae, which undergoes a limited number of divisions before entering senescence and dying. During the senescence process, $S$. cerevisiae has been recently shown to accumulate extrachromosomal rDNA circles that lead to a massive increase of unprocessed pre-rRNA in the nucleolus, resulting in loss of nuclear homeostasis with increase of the nucleus 
size and accumulation of nuclear proteins [73]. TbRrp44 knockdown T. brucei cells and senescent $S$. cerevisiae cells share one feature, which is the accumulation of unprocessed pre-rRNA. At this stage, we cannot rule out that accumulation of unprocessed pre-rRNA may affect nuclear homeostasis and participate in the signals that lead to inhibition of cell proliferation.

Despite the relative mild defects observed in the cell cycle and cell membrane, TbRrp44 knockdown cells showed striking morphological and biochemical changes. This fact, combined with the defect in ribosome maturation [27,29], led us to hypothesize that some alterations could be determined by autofluorescence quantification. Differences in total autofluorescence emission was observed in TbRrp44 knockdown cells in the emission ranges where both the protein chromophores (tyrosine and tryptophan) and the electron carrier metabolic co-factors $\mathrm{NAD}(\mathrm{P}) \mathrm{H}$ and FAD are the major contributors. For the tyrosine, tryptophan and $\mathrm{NAD}(\mathrm{P}) \mathrm{H}$ emission ranges, most of this increase can be attributed to the larger size shown by TbRrp44 knockdown cells, since the differences in the ratio of fluorescence intensity per cell area were not significant. At longer times of TbRrp44 depletion, however, the ratio of intensity per cell area was significantly higher for tryptophan fluorescence. This increase does not seem to be directly related to increase in protein content. It is well established that tryptophan fluorescence emission depends on the interactions with the local environment, which can affect both peak position and intensity of the emission spectra [74]. Possibly, the alterations in protein organization caused by the extent of intracellular changes in TbRrp44 knockdown cells influence the quenching effect of nearby molecules on tryptophan, in a way different from the control cells, where the proteins are in native conditions.

The autofluorescence of $T$. brucei control cells in the green range (512-542 nm), where FAD is considered to be the major contributor, is consistent with the data reported for the trypanosomatid species $L$. tarantolae, in which the mitochondrion was identified as the major source of the autofluorescence in this range [47]. Both the total fluorescence intensity and the ratio of intensity per cell area in the 512-542 nm range are much higher in TbRrp44 knockdown cells, indicating strong alteration of energy metabolism in these cells. The mitochondrial activity is also affected in TbRrp44 knockdown cells as showed by reduced MitoTracker fluorescence. Reduced mitochondrial activity could explain accumulation of the oxidized FAD form as TbRrp44 knockdown cells may not be able to convert FAD into its reduced form $\mathrm{FADH}_{2}$ with the same efficiency as the control cells. The loss of the mitochondrial membrane potential as detected by their failure to oxidize MitoTracker is also one of the initial signals of activation of cell death mechanisms.

The analyses performed with 3D cryo soft X-ray reconstructions provided detailed evidence of the ultrastructural alterations that take place in TbRrp44 cells. Alterations in the nucleus, nucleolus and mitochondria localization and structure are observed in TbRrp44 knockdown cells along with a general enlargement of all vesicles. The most striking alteration involves formation of low absorption vacuoles. Reconstitution of the three-dimensional cell structures showed that the low absorption vacuoles can increase in size and number and occupy most of the cytoplasmic space.

Acidocalcisomes were localized by using images acquired at the calcium pre- and $\mathrm{L}_{2,3^{-}}$ edges. Volume calculation confirmed that acidocalcisomes increase in size in TbRrp44 knockdown cells, but they are not the vesicles that make the largest contribution to vacuolation. Our analyses also provided direct evidence to distinguish the acidocalcisomes from lipid droplets, which contain lipids at high density and are the organelles showing the highest 
absorption in the soft X-ray range [63-66]. Both the number per cell and the size of lipid droplets observed in the 3D reconstructed knockdown cells are two times higher than in control cells. Nile Red fluorescence can be useful to quantify lipid droplets, although it does not show a resolution equivalent to cryo-SXT. The increase in size and number of lipid droplets contributes to the general enlargement of vesicles in TbRrp44 knockdown cells and represents the unusual accumulation of lipids in these cells.

The vesicles stained with LysoTracker and those containing the lysosomal membrane protein p67 marker [54] are the ones showing the highest increase in size in TbRrp44 knockdown cells. Therefore, the large acidic vesicles should be derived from lysosomes and should also correspond to the low absorbing vacuoles observed in the 3D cryo soft X-ray reconstructions. The discrepancy between the data obtained from the p67-GFP and p67-HA quantifications may be due to fact that GFP emission requires a protein in native state and lysosomes seem to be totally altered in knockdown cells. Formation and expansion of lysosome-derived structures in $T$. brucei has a correlation with cell death processes [50-53]. The different degrees of vacuolation suggest that TbRrp44 knockdown cells are at different stages of a death process with the cytoplasm being taken up by lysosome-derived vacuoles.

In conclusion, the multidisciplinary approach based on Synchrotron DUV microscopy, cryo soft X-ray tomography and fluorescence imaging used in this work provided for the first time a detailed description of drastic ultrastructural cellular defects that are taking place in $T$. brucei cells, after depletion of an essential protein, the Rrp44 ribonuclease. Vacuolation of the cytoplasm and global enlargement of cellular vesicles and organelles are especially highlighted by cryo soft $X$-ray tomography and reconstructed $3 \mathrm{D}$ volumes. The signals driving formation and progression of the lysosome-derived vacuoles converge from a combination of defects in TbRrp44-depleted cells, which comprise accumulation of unprocessed pre-rRNA, disruption of ribosome synthesis, activation of the autophagy response, mitochondrial inactivation and loss of cell membrane asymmetry and nuclear DNA damage. 
bioRxiv preprint doi: https://doi.org/10.1101/2020.02.29.971424; this version posted February 29, 2020. The copyright holder for this preprint (which was not certified by peer review) is the author/funder, who has granted bioRxiv a license to display the preprint in perpetuity. It is made available under aCC-BY-NC-ND 4.0 International license.

\section{Materials and Methods}

\section{Trypanosoma brucei 29-13 derivative strains}

Construction of a Trypanosoma brucei brucei [here designated as Trypanosoma brucei ( $T$. brucel) for simplification] strain for conditional depletion of the TbRrp44 was described in a previous work of our group [29]. Procyclic cells of the parental T. brucei 29-13 strain were maintained in SDM 79 supplemented with $10 \%(\mathrm{v} / \mathrm{v})$ bovine calf serum, hygromycin $(50 \mu \mathrm{g} / \mathrm{mL})$ and G418 $(15 \mu \mathrm{g} / \mathrm{mL})$. The medium for the conditional strain also contained phleomycin (2.5 $\mu \mathrm{g} / \mathrm{mL}$ ). The conditional strain was also transformed with a plasmid expressing the autophagy marker Atg8.2 fused to the yellow fluorescence protein. Plasmid pGL2166 [34] was kindly provided by Jeremy Mottram (Centre for Immunology and Infection, University of York, UK).

\section{Induction of RNA interference and cell fixation with paraformaldehyde (PFA)}

Cells from fresh cultures at a density of $1-5 \times 10^{7}$ cells $/ \mathrm{mL}$ were inoculated in two cultures of 10 $\mathrm{mL}$ SDM 79 supplemented with $10 \%(\mathrm{v} / \mathrm{v})$ bovine calf serum containing hygromycin (50 $\mu \mathrm{g} / \mathrm{mL}), \mathrm{G} 418(15 \mu \mathrm{g} / \mathrm{mL})$ phleomycin $(2.5 \mu \mathrm{g} / \mathrm{mL})$ and maintained at $28^{\circ} \mathrm{C}$. RNA interference was induced every $24 \mathrm{~h}$ with tetracycline $(2 \mu \mathrm{g} / \mathrm{mL}$ at time 0 followed by $1 \mu \mathrm{g} / \mathrm{mL}$ every 24 hours). Cells from the TbRrp44 conditional strain were collected at 48,72 and 96 hours after RNAi induction. For each time point, samples grown in parallel without induction with tetracycline were collected as controls. After each incubation time, cells were centrifuged at $3000 \mathrm{~g}$ for $5 \mathrm{~min}$, washed with phosphate buffered saline (PBS, $10 \mathrm{mM}$ sodium phosphate buffer $\mathrm{pH} 7.4,138 \mathrm{mM} \mathrm{NaCl}, 27 \mathrm{mM} \mathrm{KCl}$ ) and fixed with $4 \%(\mathrm{v} / \mathrm{v})$ paraformaldehyde (PFA) in PBS at room temperature for $10 \mathrm{~min}$. Subsequently, the cells were washed again, suspended in PBS and maintained at $4^{\circ} \mathrm{C}$ for analysis.

\section{Deep UV image acquisition and analysis}

Autofluorescence images in deep ultraviolet DUV were acquired at Synchrotron SOLEIL's DISCO beamline [42] equipped with a modified Zeiss Axio Observer Z1, using a 100× Zeiss ultrafluar objective and an EM-CCD camera (Princeton Pixis 1024-BUV). The excitation wavelength was set at $275 \mathrm{~nm}$ for utilization of maximum flux of this beamline and fluorescence emission were recorded in the 307-323, 327-353 and 451-486 nm wavelength ranges for 40 seconds of integration time. Brightfield images were acquired using 100 milliseconds integration time. For illumination correction, white and dark images for each emission wavelength range were also acquired using the same settings. Images were analyzed using the Fiji image processing package of ImageJ (http://imagej.net/Fiii; https://imagej.nih.gov/ii/) [75]. Before quantitation of fluorescence intensity, images were corrected using the relation Ic $=(\mathrm{I}-\mathrm{d}) /(\mathrm{w}-\mathrm{d}) \quad$ (Ic: image corrected, d: dark image, w: white image, I: raw image). The Process/FFT/bandpass filter command was applied to each fluorescence image before inverting them and setting default threshold to define the outline of the cells to be quantified using the analyze particles command. Background was subtracted using the rolling ball radius algorithm. Fluorescence intensity and cell area were determined using the multi measure plugin.

\section{Cell cycle analysis by flow cytometry}

For cell cycle analyses, control and TbRRP44 knockdown cells were collected 48, 72 and 96 hours after RNAi induction. The cells were centrifuged at $300 \mathrm{~g}$ for $10 \mathrm{~min}$, washed with PBS and fixed with cold ethanol $70 \%\left(5 \times 10^{6} / \mathrm{mL}\right)$ at $-20{ }^{\circ} \mathrm{C}$. The cells were harvested by centrifugation, washed with PBS and suspended in $200 \mu \mathrm{L}$ PBS plus $200 \mu \mathrm{L}$ of the propidium iodide staining solution (3.4 mM Tris. $\mathrm{HCl} \mathrm{pH}$ 7.4, 0.1\% NP40 (v/v), $10 \mathrm{mg} / \mathrm{mL}$ RNase A, 10 
$\mathrm{mM} \mathrm{NaCl}, 30 \mu \mathrm{g} / \mathrm{mL}$ propidium iodide). Data from 10,000 events per sample were acquired using a FACS Canto II (BD Biosciences). The propidium iodide fluorochrome was excited with a blue laser $(488 \mathrm{~nm})$ and the emitted fluorescence was collected with a 585/42 band pass filter. Single cells were gated based on PI-A vs. PI-W [76]. The cell samples were stained and analyzed in triplicate. Data analysis was performed using the FlowJo software version 10.6.1.

\section{Analysis of cell death using annexin V-Alexa 488 and propidium iodide staining}

A total of $2 \times 10^{6}$ cells from control and TbRRP44 knockdown cells from 48, 72 and 96 hours after RNAi induction were centrifuged at $300 \mathrm{~g}$ for $10 \mathrm{~min}$, washed once with PBS and stained with Alexa Fluor 488 annexin V/Dead Cell Apoptosis Kit (Invitrogen - V13245) according to the manufacturer's instructions. The analyses (20.000 events/sample) were performed on a FACS Canto II (BD Biosciences). Alexa Fluor 488-annexin V and propidium iodide fluorochromes were excited with a blue laser $(488 \mathrm{~nm})$ and the emitted light was collected with 530/30 and $585 / 42$ band pass filters, respectively. Color compensation was used to minimize spectral overlap. The cell samples were stained and analyzed in triplicate. Data analysis was performed using the FlowJo software version 10.6.1.

\section{Nucleus and kinetoplast quantification}

Control and TbRrp44 knockdown cells were collected at 48 and 72 hours after RNAi induction and fixed with $4 \%(\mathrm{v} / \mathrm{v})$ PFA $\left(\sim 3 \times 10^{6} \mathrm{cells} / \mathrm{mL}\right)$ as described above. The cells were adhered to CellCarrier-96 Ultra Microplates (PerkinElmer) precoated with poly-L-lysine and stained with $2 \mu \mathrm{g} / \mathrm{mL}$ of DAPI (4',6-Diamidino-2-Phenylindole). The images were acquired on an Operetta CLS High-Content Analysis System (PerkinElmer) using the confocal model, z-stack function (four planes at intervals of $0.5 \mu \mathrm{m}$ ) and a $63 x$ water objective lens (NA 1.15 and WD 0.6). The DAPI signal was collected using 355-385 nm excitation and 430-500 nm emission filters. Maximum projection images from Z-planes were analyzed with Harmony 4.6 software. Cells were detected using the "find cell" algorithm (method A) in digital phase contrast (high detail) image. Border cells were excluded and only entire cells were kept in the analysis. Isolate cells were selected based on morphology properties (width and area). Nuclei and kinetoplasts were identified as spots (method B) in DAPI images and were distinguished based on the area and roundness properties. The output results represent the percentage of $1 \mathrm{~N} / 1 \mathrm{~K}, 1 \mathrm{~N} / 2 \mathrm{~K}$ and $2 \mathrm{~N} / 2 \mathrm{~K}$ cells. The data was obtained in duplicate.

\section{Analysis of autofluorescence in the green range and staining with MitoTracker}

For analysis of autofluorescence in the green wavelength range, control and TbRrp44 knockdown cells were collected 72 hours after RNAi induction and fixed with $4 \%$ PFA (v/v) as described above. Autofluorescence in the green wavelength range was acquired on a Leica Microsystems DMI6000B microscope using an HCX PL APO 100x/1.40 oil objective. This microscope is equipped with a DFC365 FX camera and operated with Leica Application Suite. Acquisition time was 5 seconds for autofluorescence $(460-500 \mathrm{~nm}$ bandpass filter for excitation and a 512-542 $\mathrm{nm}$ bandpass filter for emission) and 100 milliseconds for brightfield images.

For MitoTracker staining, $10 \mathrm{nM}$ MitoTracker Orange CMTMROS (Molecular Probes/ThermoFisher) were added to cultures of control and TbRrp44 knockdown cells 72 hours after RNAi induction. The cells were incubated for further $30 \mathrm{~min}$, washed with PBS and fixed with $4 \%(\mathrm{v} / \mathrm{v})$ PFA as described above. Images of MitoTracker-stained cells were acquired on a Nikon Eclipse 80i microscope using a Planfluor 100x/1.30 objective, Evolution MP Color camera (Media Cybernetics) and QCapture Pro 6.0 software. The acquisition time of MitoTracker fluorescence images was 4 seconds using a 528-553 nm bandpass filter for 
excitation and a 590-650 nm filter for emission. Images were rescaled using the Analyze Menu tools of Fiji [71] to convert image size from pixels to $\mu \mathrm{m}$. Definition of cell contour, subtraction of background and fluorescence and area quantitation were performed as described above.

\section{Amino acid starvation and autophagosome analyses}

Autophagosomes were analyzed using TbRrp44 conditional strain transformed with plasmid pGL2166 expressing the autophagosome marker ATG8.2 fused to the yellow fluorescent protein [34]. The cells were cultivated under permissive and knockdown conditions and collected for analysis at 48 and $72 \mathrm{~h}$ after knockdown of TbRrp44. Induction of autophagosome formation was carried out as described by Li et al. (2012) [32] using gPBS (PBS containing $1 \mathrm{~g} / \mathrm{L}$ glucose) instead of gHBSS. The cells were washed twice with gPBS (PBS containing $1 \mathrm{~g} / \mathrm{L}$ glucose), suspended in gPBS at $1-3 \times 10^{6}$ cells $/ \mathrm{mL}$ and incubated at $28^{\circ} \mathrm{C}$ for 2 hours. Subsequently, the cells were fixed with $4 \%$ PFA as described above and adhered to poly-L-lysine-treated microscope slides. The cells were permeabilized with $0.25 \%$ (v/v) NP40 in PBS buffer for 2 minutes and blocked with 4\% bovine serum albumin in PBS buffer for 1 hour. Atg8.2-YFP was localized by immunostaining with an anti-GFP nanobody (clone LAg16-G4S-2, [77]) conjugated with Alexa Fluor 488 and simultaneously stained with a $1: 1500$ dilution of a $1 \%$ Evans Blue $(\mathrm{v} / \mathrm{v})$ solution. Images were acquired on a Leica Microsystems DMI6000B microscope using the same objective and set of filters described above for the analysis of autofluorescence in the green range. The images were analyzed with Columbus Image Data Storage and Analysis System for Microscopy (PerkinElmer). Cells were detected using "find cell" algorithm (method A) from the Evans blue signal (red channel). Border objects were excluded to analyze only entire cells. Isolate cells were selected with the morphology (roundness and area) properties. Autophagosomes were identified from Alexa fluor 488 signal (green channel) with "find spots" algorithm (method C) and the percentage of cells with autophagosome was calculated. The data were obtained from 10 images of each experimental condition.

\section{PCR-based tagging of mitochondrial and lysosomal protein markers}

The G418 genetic resistance marker from plasmids PMOTAG3H and pMOTAG3G [78] was replaced by the puromycin resistance gene. The resulting plasmids (pMO-HA-Puro and pMO-GFP-Puro) were used in PCR reactions to amplify the puromycin gene flanked by sequences of the target genes for introducing $\mathrm{C}$-terminal tags into the mitochondrial heat shock protein 40 (mtHSP40, gene ID: Tb427tmp.211.3680) and the lysosomal/endosomal membrane protein p67 (p67.1, gene ID: Tb427.05.1810). The PCR products were transformed into the $T$. brucei strain conditional for TbRrp44 expression, which was described in a previous study [29]. Following transfection, homologous recombination of the PCR products results in insertion of the tags sequences in the respective genes together with the puromycin resistance gene, which was used for selection of positive transfectants. Following selection with puromycin (2 $\mu \mathrm{g} / \mathrm{mL})$, transfectant cells were maintained in SDM 79 supplemented with $10 \%(\mathrm{v} / \mathrm{v})$ bovine calf serum, hygromycin $(50 \mu \mathrm{g} / \mathrm{mL}), \mathrm{G} 418(15 \mu \mathrm{g} / \mathrm{mL})$, phleomycin $(2.5 \mu \mathrm{g} / \mathrm{mL})$ and puromycin (4 $\mu \mathrm{g} / \mathrm{mL}$ ). Double-stranded RNA expression for RNA interference was induced with tetracycline $(2 \mu \mathrm{g} / \mathrm{mL}$ at time 0 followed by $1 \mu \mathrm{g} / \mathrm{mL}$ every 24 hours), as described above.

\section{Protein localization by fluorescence and indirect immunofluorescence microscopy}

For analysis of p67.1-GFP tagged localization, live procyclic control and TbRrp44 knockdown cells were collected 48 and 72 hours after RNAi induction, concentrated to $\sim 10^{8}$ cells $/ \mathrm{mL}$ and mounted on microscope slides. Images were acquired on a Leica Microsystems 
DMI6000B microscope using the same objective and set of filters described above for analysis of the autofluorescence except for the acquisition time that was $1 \mathrm{~s}$ and $1.5 \mathrm{~s}$ for the cells collected at the 48 and $72 \mathrm{~h}$ time points, respectively. For indirect immunofluorescence analysis of HA-tagged proteins, control and TbRrp44 knockdown cells were collected at 48 and 72 hours after RNAi induction, fixed with 4\% (v/v) PFA ( 3 $\times 10^{6}$ cells $\left./ \mathrm{mL}\right)$ as described above and adhered to slides precoated with poly-L-lysine. To immunolabel mtHSP40-HA, the cells were permeabilized with $0,1 \%(\mathrm{v} / \mathrm{v})$ triton $\mathrm{X}-100$ in PBS buffer for 2 minutes and blocked with $4 \%(\mathrm{w} / \mathrm{v})$ of bovine serum albumin in PBS buffer for 1 hour. To immunolabel p67.1-HA, the cells were permeabilized and blocked with saponin solution (1\% v/v saponin, $2 \% \mathrm{w} / \mathrm{v}$ bovine serum albumin in PBS buffer) for 1 hour. Subsequently, the cells were incubated with the anti-HA high affinity antibody (3F10) (1:500 dilution, Roche - cat. 11867423001), followed by incubation with an anti-rat secondary antibody conjugated to Alexa Fluor 488 (1:2000 dilution, Molecular Probes - cat. A21210) and $2 \mu \mathrm{g} / \mathrm{mL}$ of DAPI. Images were acquired on a Leica Microsystems DMI6000B microscope using the same objective and set of filters described above. The acquisition time of p67.1-HA and mtHSP40-HA fluorescence images was $500 \mathrm{~ms}$ and $300 \mathrm{~ms}$, respectively, using a 460-500 $\mathrm{nm}$ bandpass filter for excitation and a 512-542 $\mathrm{nm}$ bandpass filter for emission. Images were analyzed using the Fiji image processing package of ImageJ (http://imagej.net/Fiij; https://imagej.nih.gov/ij/) [75] as described above.

\section{Cell preparation for cryo soft X-ray tomography and cryo spectromicroscopy}

Induction of RNA interference was performed as described above and cells were collected at 48 and 72 hours after induction. In initial attempts of grid preparation, TbRrp44 knockdown cells appeared to be very fragile as they "compressed", assuming a flat conformation (S3 Fig). On the other hand, wild type procyclic T. brucei cells are fast moving and did not adhere well to poly-lysine treated grids. Both problems were overcome by a quick fixation step with $2 \%$ paraformaldehyde (PFA) as follows: $1 \mathrm{~mL}$ of a cell culture containing $\sim 10^{7}$ cells $/ \mathrm{mL}$ was centrifuged, washed in $500 \mu \mathrm{L}$ PBS, quick-fixed in $500 \mu \mathrm{L}$ PBS containing $2 \%$ PFA (v/v) for $3 \mathrm{~min}$ at room temperature and washed again with $500 \mu \mathrm{L}$ PBS. All centrifugation steps were at $800 \mathrm{~g}$ for $5 \mathrm{~min}$ at room temperature. The PFA quick-fixed cells were suspended $100 \mu \mathrm{L}$ PBS at $\sim 10^{8}$ cells $/ \mathrm{mL}$. Before cell deposition, the carbon side of gold quantifoil $\mathrm{R} 2 / 2$ holey carbon-film microscopy grids (Au-G200F1) were treated with $20 \mu \mathrm{L}$ of poly-L-lysine in a humidity-controlled chamber at $37^{\circ} \mathrm{C}$ for $30 \mathrm{~min}$. The grids were washed twice with MilliQ water and $4 \mu \mathrm{L}$ of $100 \mathrm{~nm}$ gold nanoparticles $\left(5.6 \times 10^{\%} / \mathrm{mL}\right)$ were deposited on each grid, which were let dry under a clean bench. $5 \mu \mathrm{L}$ of cells $\left(\sim 10^{8}\right.$ cells $\left./ \mathrm{mL}\right)$ were deposited on the grids and vitrified by plunge freezing using a Leica Automatic Plunge Freezer EM GP2. The PFA treatment preserved the morphology of the cells and organelles, which allowed for comparison of the volumes and ultrastructural alterations that occur upon downregulation of TbRrp44. However, PFA interferes with the linear absorbance coefficient (LAC) (S3 Fig) preventing quantitative comparison of LAC between the organelles of control and TbRrp44 knockdown cells, as well as comparison with the LAC of other tissues.

\section{Acquisition of cryo soft X-ray tomography data sets and 3D volume reconstruction}

Cryo soft X-ray tomography data were collected at the MISTRAL beamline (Synchrotron ALBA, Barcelona Spain) [79]. The vitrificated grids were transferred to the beamline under cryogenic and vacuum conditions. The data sets were acquired at $520 \mathrm{eV}$ 
bioRxiv preprint doi: https://doi.org/10.1101/2020.02.29.971424; this version posted February 29, 2020. The copyright holder for this preprint (which was not certified by peer review) is the author/funder, who has granted bioRxiv a license to display the preprint in perpetuity. It is made available under aCC-BY-NC-ND 4.0 International license.

energy with $1 \mathrm{sec}$ of exposure, in a tilt range from -70 to 70 degrees, rotating 1 degree between each image. Alignment of the tilted series was performed with IMOD [80] using the gold fiducial markers. Final reconstructions were performed using Tomo3D [81] and cell segmentation was performed using the Amira 3D Software for Life Sciences (ThermoFisher Scientific).

\section{Cryo soft X-ray spectromicroscopy}

In order to analyze the calcium content in the cells, cryo spectromicroscopy was performed and XANES spectra of the Ca-containing vesicles were analyzed plotting the average intensity of the pixels of the vesicles area as a function of the energy (from calcium pre-edge to calcium post-edge). All vesicles spectra showed the $\mathrm{Ca}$ in solution form [57]. Calcium localization in different controls and TbRrp44 knockdown cells was carried out by subtracting an image of the cell taken at pre-edge from the one taken at the L3-edge. The contrast in the difference image is dominated by areas containing substantial Ca content. Image subtractions were carried out using the Fiji software [75]. The volumes of acidocalcisomes were calculated using the Microscopy Image Browser software platform [82]. The organelles were manually segmented, the volumes obtained in pixel ${ }^{3}$ and then converted into $\mu \mathrm{m}^{3}$. Statistical analyses were performed using GraphPad Prism version 7.01 software.

\section{Lipid droplet quantification}

The volumes of lipid droplets from cryo-SXT reconstructed cells were calculated as described above for the acidocalcisomes. For Red Nile staining of lipid droplets, $2 \mathrm{~mL}$ of control and TbRrp44 knockdown cells were collected 48 and 72 hours after RNAi induction, fixed with $4 \%$ PFA $\left(\sim 3 \times 10^{6}\right.$ cells $\left./ \mathrm{mL}\right)$ as described above and adhered to 96-well plate precoated with poly-L-lysine. The cells were incubated with $1 \mu \mathrm{g} / \mathrm{mL}$ of Nile red and $2 \mu \mathrm{g} / \mathrm{mL}$ of DAPI $\left(4^{\prime}, 6-\right.$ Diamidino-2-Phenylindole) for 30 minutes. The images were acquired on an Operetta CLS High-Content Analysis System (PerkinElmer) using the confocal model, z-stack function (three planes at intervals of $0.5 \mu \mathrm{m}$ ) and a $63 x$ water objective lens (NA 1.15 and WD 0.6). The DAPI signal was collected using 355-385/430-500 nm excitation/emission filters. Nile red signals was collected using 460-490/500-550 (green) and 615-645/655-760 (red) excitation/emission filters. Maximum projection images from Z-planes were analyzed with Harmony 4.6 software. Cells were detected using the "find cell" algorithm (method $\mathrm{C}$ ) using the red images. Border cells were excluded and only entire cells were kept in the analysis. Isolated cells were selected based on morphology properties (width, length, area and roundness). The intensity average of the green fluorescence signal from the selected cells was used for comparisons.

\section{Analysis of cells stained with LysoTracker}

LysoTracker staining was performed on living cells. Control and TbRrp44 knockdown cells were collected 72 hours after RNAi induction, washed with PBS, stained with $10 \mathrm{nM}$ of LysoTracker Green DND-26 (Molecular Probes/ThermoFisher) and mounted on microscope slides. The images were acquired on a Leica Microsystems DMI6000B microscope using the same objective and set of filters as described above for autofluorescence, using 0.5 seconds of acquisition time. The images were rescaled using the Analyze Menu tools of Fiji (http://imagej.net/Fiij; https://imagej.nih.gov/ij/) [75] to convert image size from pixels to $\mu \mathrm{m}$. Definition of cell contour, subtraction of background and fluorescence and area quantitation were performed as described above.

\section{Statistical analysis}

The data are presented as the mean \pm standard error of the number of cells analyzed and measurements performed. Differences between two samples were assessed by t-test. 
Differences between four or more samples were assessed one-way analysis of variance (ANOVA) followed by Tukey's multiple comparison test using GraphPad Prism version 7.01 software. *: $0.01<p<0.05 ;{ }^{* *}: 0.001<p<0.01 ;{ }^{* * *}: p<0.001$.

\section{Transmission electron microscopy}

Control and TbRrp44 knockdown procyclic forms were collected from the culture media by centrifugation for $10 \mathrm{~min}$ at $3.500 \mathrm{~g}$, washed with PBS and fixed for 2 hours with $2.5 \%$ glutaraldehyde in $0.1 \mathrm{M}$ cacodylate buffer $\mathrm{pH} 7.2$. The cells were thereafter washed in $0.1 \mathrm{M}$ cacodylate buffer and post-fixed for 1 hour with $1 \%$ osmium tetroxide / $0.8 \%$ potassium

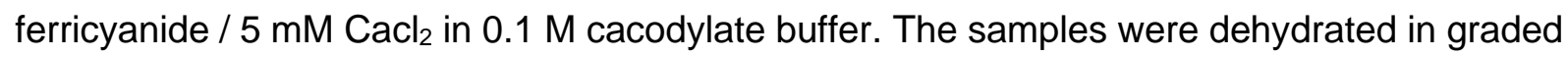
acetone series and embedded for 72 hours at $60^{\circ} \mathrm{C}$ in Embed-812 resin (EMS, Hatfield, PA, USA). Ultrathin sections were collected on copper grids, stained for 30 min with uranyl acetate and for 2 min with lead citrate, and observed under a Jeol 1400Plus transmission electron microscope operated at $80 \mathrm{kV}$. Digital images were acquired and then processed for better contrast using Adobe Photoshop CS5 (Adobe Systems, Inc.). 


\section{Acknowledgements}

The authors are grateful for the following institutions and people:

Synchrotron SOLEIL for beam time awarded at DISCO beamline (proposal 20160888) and all the support they benefited as SOLEIL's users. Synchrotron ALBA for beam time awarded at MISTRAL beamline (proposals 2017022087, 2018022705) and all the support they benefited as ALBA's users. FIOCRUZ Network of Technological Platforms for access to its facilities (Platforms RPT07C - Confocal and Electron Microscopy and RPT08L - Flow Cytometry). Dr. Bruna H. Marcon for support with the analyses performed at Platform RPT07C. Prof. Jeremy Mottram, Centre for Immunology and Infection, University of York, United Kingdom, for providing plasmids pGL2165 and pGL2166. Funding was provided by CAPES-COFECUB program (CAPES 862/2015, - COFECUB Me862-15), CNPq (NITZ: 312195/2015-0; BGG: 304027/2015-4), FIOCRUZ Inova program (3501948026).

\section{Author contributions}

N.I.T. Zanchin, B.G. Guimarães, F. Jamme. and M. Réfrégiers designed the experiments and the working plan. N.I.T. Zanchin, F. Jamme, G. Cesaro, B.G. Guimarães, and M. Réfrégiers collected and analyzed fluorescence data. F. Jamme, E. Pereiro, J.J. Conesa and N.I.T. Zanchin planned the experiments and prepared the samples for cryo-soft X-ray tomography. F. Jamme, E. Pereiro, G. Cesaro, N.I.T. Zanchin, B.G. Guimarães, P. Legrand collected and analyzed the cryo-soft X-ray tomography data. P.M. Hiraiwa and N.I.T. Zanchin designed the PCR-base experiments for tagging of proteins. P.M. Hiraiwa and F.R.G. Carneiro established the conditional strains and performed microscopic, flow cytometry and high content image analyses. G. Cesaro and V. Rouam performed cell cultures. M.J. Soares performed electron microscopy analyses. N.I.T. Zanchin wrote the manuscript with input from other authors.

Competing interests: The authors declare no competing financial interest. 
bioRxiv preprint doi: https://doi.org/10.1101/2020.02.29.971424; this version posted February 29, 2020. The copyright holder for this preprint (which was not certified by peer review) is the author/funder, who has granted bioRxiv a license to display the preprint in perpetuity. It is made available under aCC-BY-NC-ND 4.0 International license.

\section{References}

1. Günzl A. The pre-mRNA splicing machinery of trypanosomes: complex or simplified? Eukaryot Cell. 2010;9: 1159-1170.

2. Preußer C, Jaé N, Bindereif A. mRNA splicing in trypanosomes. Int J Med Microbiol. 2012;302: 221224.

3. Gao H, Juri Ayub M, Levin ML, Frank J. The structure of the $80 \mathrm{~S}$ ribosome from Trypanosoma cruzi reveals unique rRNA components. Proc Natl Acad Sci USA. 2005;102: 10206-10211.

4. Hashem Y, des Georges A, Fu J, Buss SN, Jossinet F, Jobe A, et al. High-resolution cryo-electron microscopy structure of the Trypanosoma brucei ribosome. Nature. 2013;494: 385-389.

5. Hernández R, Cevallos AM. Ribosomal RNA gene transcription in trypanosomes. Parasitol Res. 2014;113: 2415-2424.

6. Dziembowski A, Lorentzen E, Conti E, Séraphin B. A single subunit, Dis3, is essentially responsible for yeast exosome core activity. Nat Struct Mol Biol. 2007;14: 15-22

7. Lebreton A, Tomecki R, Dziembowski A, Séraphin B. Endonucleolytic RNA cleavage by a eukaryotic exosome. Nature. 2008;456: 993-996

8. Allmang C, Kufel J, Chanfreau G, Mitchell P, Petfalski E, Tollervey D. Functions of the exosome in rRNA, snoRNA and snRNA synthesis. EMBO J. 1999;18: 5399-4410.

9. Schneider C, Kudla G, Wlotzka W, Tuck A, Tollervey D. Transcriptome-wide analysis of exosome targets. Mol Cell. 2012;8: 422-433.

10. Houseley J, LaCava J, Tollervey D. RNA-quality control by the exosome. Nat Rev Mol Cell Biol. 2006;7: 529-539.

11. Gudipati RK, Xu Z, Lebreton A, Séraphin B, Steinmetz LM, Jacquier A, Libri D. Extensive degradation of RNA precursors by the exosome in wild-type cells. Mol Cell. 2012;48: 409-421.

12. Shiomi T, Fukushima K, Suzuki N, Nakashima N, Noguchi E, Nishimoto T. Human dis3p, which binds to either GTP- or GDP-Ran, complements Saccharomyces cerevisiae dis3. J. Biochem. 1998;123: 883-890.

13. Kumakura N, Otsuki H, Tsuzuki M, Takeda A, Watanabe Y. Arabidopsis AtRRP44A is the functional homolog of Rrp44/Dis3, an exosome component, is essential for viability and is required for RNA processing and degradation. PLoS One. 2013;8: e79219

14. Ohkura H, Adachi $Y$, Kinoshita N, Niwa O, Toda T, Yanagida M. Cold-sensitive and caffeinesupersensitive mutants of the Schizosaccharomyces pombe dis genes implicated in sister chromatid separation during mitosis. EMBO J. 1988;7: 1465-1473.

15. Kinoshita N, Goebl M, Yanagida M. The fission yeast dis3+ gene encodes a 110-kDa essential protein implicated in mitotic control. Mol Cell Biol. 1991;11: 5839-5847.

16. Murakami H, Goto DB, Toda T, Chen ES, Grewal SI, Martienssen RA, Yanagida M. Ribonuclease activity of Dis3 is required for mitotic progression and provides a possible link between heterochromatin and kinetochore function. PLoS One 2007;21: e317.

17. Mitchell $P$, Petfalski E, Tollervey D. The $3^{\prime}$-end of yeast $5.8 S$ rRNA is generated by an exonuclease processing mechanism. Genes and Dev. 1996;10: 502-513.

18. Mitchell P, Petfalski E, Shevchenko A, Mann M, Tollervey D. The exosome: A conserved eukaryotic RNA processing complex containing multiple $3^{\prime} \rightarrow 5^{\prime}$ exoribonuclease activities. Cell. 1997;91: 457466.

19. Allmang C, Petfalski E, Podtelejnikov A, Mann M, Tollervey D, Mitchell P. The yeast exosome and human PM-Scl are related complexes of 3' > 5' exonucleases. Genes Dev. 1999;13: 2148-2158.

20. Milbury KL, Paul B, Lari A, Fowler C, Montpetit B, Stirling, PC. Exonuclease domain mutants of yeast DIS3 display genome instability. Nucleus. 2019;10: 21-32.

21. Zhang W, Murphy C, Sieburth LE. Conserved RNasell domain protein functions in cytoplasmic mRNA decay and suppresses Arabidopsis decapping mutant phenotypes. Proc Natl Acad Sci USA. 2010;107: 15981-15985.

22. Hou D, Ruiz M, Andrulis ED. The ribonuclease Dis3 is an essential regulator of the developmental transcriptome. BMC Genomics. 2012;13: 359. 
bioRxiv preprint doi: https://doi.org/10.1101/2020.02.29.971424; this version posted February 29, 2020. The copyright holder for this preprint (which was not certified by peer review) is the author/funder, who has granted bioRxiv a license to display the preprint in perpetuity. It is made available under aCC-BY-NC-ND 4.0 International license.

23. Snee MJ, Wilson WC, Zhu Y, Chen SY, Wilson BA, Kseib C, et al. Collaborative Control of Cell Cycle Progression by the RNA Exonuclease Dis3 and Ras Is Conserved Across Species. Genetics 2016;203: 749-762.

24. Segalla S, Pivetti S, Todoerti K, Chudzik MA, Giuliani EC, Lazzaro F, et al. The ribonuclease DIS3 promotes let-7 miRNA maturation by degrading the pluripotency factor LIN28B mRNA. Nucleic Acids Res. 2015;43: 5182-5193.

25. Weissbach S, Langer C, Puppe B, Nedeva T, Bach E, Kull M, et al. The molecular spectrum and clinical impact of DIS3 mutations in multiple myeloma. Br J Haematol. 2015;169: 57-70.

26. Lionetti M, Barbieri M, Todoerti K, Agnelli L, Fabris S. Tonon G, et al. A compendium of DIS3 mutations and associated transcriptional signatures in plasma cell dyscrasias. Oncotarget. 2015;6: 26129-26141.

27. Estévez AM, Kempf T, Clayton C. The exosome of Trypanosoma brucei. EMBO J. 2001;20: 38313829.

28. Estévez AM, Lehner B, Sanderson CM, Ruppert T, Clayton C. The roles of intersubunit interactions in exosome stability. J Biol Chem. 2003;278: 34943-34951.

29. Cesaro G, Carneiro FRG, Ávila AR, Zanchin NIT, Guimarães BG. Trypanosoma brucei RRP44 is involved in an early stage of large ribosomal subunit RNA maturation. RNA Biol. 2019;16: 133-143.

30. Boulon S, Westman BJ, Hutten S, Boisvert FM, Lamond Al. The nucleolus under stress. Mol Cell. 2010;40: 216-227.

31: Pfister AS. Emerging Role of the Nucleolar Stress Response in Autophagy. Front Cell Neurosci. 2019;13: 156.

32. Li FJ, Shen Q, Wang C, Sun Y, Yuan AY, He CY. A role of autophagy in Trypanosoma brucei cell death. Cell Microbiol. 2012;14: 1242-1256.

33. Klionsky DJ, Abdelmohsen K, Abe A, Abedin MJ, Abeliovich H, Acevedo Arozena A, et al. Guidelines for the use and interpretation of assays for monitoring autophagy (3rd edition). Autophagy.2016;12: 1-222.

34. Proto WR, Jones NG, Coombs GH, Mottram JC. Tracking autophagy during proliferation and differentiation of Trypanosoma brucei. Microb Cell. 2014;1: 9-20.

35. Henry CM, Hollville E Martin SJ. Measuring apoptosis by microscopy and flow cytometry. Methods. 2013;61: 90-97.

36. Siegel TN, Hekstra DR, Cross GA. Analysis of the Trypanosoma brucei cell cycle by quantitative DAPI imaging. Mol. Biochem. Parasitol. 2008;160: 171-174.

37. Levy GV, Bañuelos CP, Níttolo AG, Ortiz GE, Mendiondo N, Moretti G, et al. Depletion of the SRrelated protein TBRRM1 leads to cell cycle arrest and apoptosis-like death in Trypanosoma brucei. PLoS One 2015;10: e0136070.

38. Kobayashi Y, Sakemura R, Kumagai A, Sumikawa E, Fujii M, Ayusawa D. Nuclear swelling occurs during premature senescence mediated by MAP kinases in normal human fibroblasts. Biosci Biotechnol Biochem. 2008;72: 1122-1125.

39. Filippi-Chiela EC, Oliveira MM, Jurkovski B, Callegari-Jacques SM, da Silva VD, Lenz G. Nuclear morphometric analysis (NMA): screening of senescence, apoptosis and nuclear irregularities. PLoS One. 2012;7: e42522.

40. Yoon KB, Park KR, Kim SY, Han SY. Induction of Nuclear Enlargement and Senescence by Sirtuin Inhibitors in Glioblastoma Cells. Immune Netw. 2016; 16:183-188.

41. Proto WR, Coombs GH, Mottram JC. Cell death in parasitic protozoa: regulated or incidental? Nat Rev Microbiol. 2013;11: 58-66.

42. Jamme F, Kascakova S, Villette S, Allouche F, Pallu S, Rouam V, Réfrégiers M. Deep UV autofluorescence microscopy for cell biology and tissue histology. Biol Cell. 2013;105: 277-288.

43. Ying $W$. NAD+/NADH and NADP+/NADPH in cellular functions and cell death: regulation and biological consequences. Antioxid Redox Signal. 2008;10: 179-206.

44. Blacker TS, Duchen MR. Investigating mitochondrial redox state using NADH and NADPH autofluorescence. Free Radic Biol Med. 2016;100: 53-65. 
bioRxiv preprint doi: https://doi.org/10.1101/2020.02.29.971424; this version posted February 29, 2020. The copyright holder for this preprint (which was not certified by peer review) is the author/funder, who has granted bioRxiv a license to display the preprint in perpetuity. It is made available under aCC-BY-NC-ND 4.0 International license.

45. Voltti $\mathrm{H}$, Hassinen IE. Oxidation-reduction midpoint potentials of mitochondrial flavoproteins and their intramitochondrial localization. J Bioenerg Biomem. 1978;10: 45-58.

46. Kunz WS, Kunz W. Contribution of different enzymes to flavoprotein fluorescence of isolated rat liver mitochondria. Biochim Biophys Acta. 1985;841: 237-246.

47. Eckers E, Deponte M. No need for labels: the autofluorescence of Leishmania tarentolae mitochondria and the necessity of negative controls. PLoS One 2012;7: e47641.

48. Peikert CD, Mani J, Morgenstern M, Käser S, Knapp B, Wenger C, Harsman A, Oeljeklaus S, Schneider A, Warscheid B. Charting organellar importomes by quantitative mass spectrometry. Nat Commun. 2017;8: 15272.

49. Týč J, Klingbeil MM, Lukeš J. Mitochondrial heat shock protein machinery hsp70/hsp40 is indispensable for proper mitochondrial DNA maintenance and replication. MBio. 2015;6: e02425-14.

50. Figarella K, Uzcategui NL, Beck A, Schoenfeld C, Kubata BK, Lang F, Duszenko M. Prostaglandininduced programmed cell death in Trypanosoma brucei involves oxidative stress. Cell Death Differ. 2006;13: 1802-1814.

51. Uzcátegui NL, Carmona-Gutiérrez D, Denninger V, Schoenfeld C, Lang F, Figarella K, Duszenko M. Antiproliferative effect of dihydroxyacetone on Trypanosoma brucei bloodstream forms: cell cycle progression, subcellular alterations, and cell death. Antimicrob Agents Chemother. 2007;51: 39603968.

52. van Zandbergen G, Lüder CG, Heussler V, Duszenko M. Programmed cell death in unicellular parasites: a prerequisite for sustained infection? Trends Parasitol. 2010;26: 477-483.

53. Barth T, Meiwes A, Mogk S, Mudogo CN, Duszenko M. Staurosporine-induced cell death in trypanosoma brucei and the role of endonuclease $G$ during apoptosis. Open Journal of Apoptosis. 2014;3: 16-31.

54. Kelley RJ, Alexander DL, Cowan C, Balber AE, Bangs JD. Molecular cloning of p67, a lysosomal membrane glycoprotein from Trypanosoma brucei. Mol Biochem Parasitol. 1999;98: 17-28.

55. Alexander DL, Schwartz KJ, Balber AE, Bangs JD. Developmentally regulated trafficking of the lysosomal membrane protein p67 in Trypanosoma brucei. J Cell Sci. 2002;115: 3253-3263.

56. Taylor MC, McLatchie AP, Kelly JM. Evidence that transport of iron from the lysosome to the cytosol in African trypanosomes is mediated by a mucolipin orthologue. Mol Microbiol. 2013; 89:420-432.

57. Schneider G, Guttmann P, Heim S, Rehbein S, Mueller F, Nagashima K, Heymann JB, Müller WG, McNally J. Three-dimensional cellular ultrastructure resolved by X-ray microscopy. Nat Methods. 2010;7: 985-987.

58. Groen J, Conesa JJ, Valcárcel R, Pereiro E. The cellular landscape by cryo soft X-ray tomography. Biophys Rev. 2019;11: 611-619.

59. Moreno SN, Docampo R. The role of acidocalcisomes in parasitic protists. J Eukaryot Microbiol. 2009;56: 208-213.

60. Docampo $R$. The origin and evolution of the acidocalcisome and its interactions with other organelles. Mol Biochem Parasitol. 2016;209: 3-9.

61. Sviben S, Gal A, Hood MA, Bertinetti L, Politi Y, Bennet M, et al. A vacuole-like compartment concentrates a disordered calcium phase in a key coccolithophorid alga. Nat Commun. 2016;7: 11228.

62. Gal A, Sorrentino A, Kahil K, Pereiro E, Faivre D, Scheffel A. Native-state imaging of calcifying and noncalcifying microalgae reveals similarities in their calcium storage organelles. Proc Natl Acad Sci USA. 2018; 115:11000-11005.

63. McDermott G, Le Gros MA, Knoechel CG, Uchida M, Larabell CA. Soft X-ray tomography and cryogenic light microscopy: the cool combination in cellular imaging. Trends Cell Biol. 2009;19: 587595.

64. Uchida M, McDermott G, Wetzler M, Le Gros MA, Myllys M, Knoechel C, et al. Soft X-ray tomography of phenotypic switching and the cellular response to antifungal peptoids in Candida albicans. Proc Natl Acad Sci USA. 2009;106: 19375-19380.

65. Uchida M, Sun Y, McDermott G, Knoechel C, Le Gros MA, Parkinson D, et al. Quantitative analysis of yeast internal architecture using soft X-ray tomography. Yeast. 2011;28: 227-236. 
bioRxiv preprint doi: https://doi.org/10.1101/2020.02.29.971424; this version posted February 29, 2020. The copyright holder for this preprint (which was not certified by peer review) is the author/funder, who has granted bioRxiv a license to display the preprint in perpetuity. It is made available under aCC-BY-NC-ND 4.0 International license.

66. Hummel E, Guttmann P, Werner S, Tarek B, Schneider G, Kunz M, et al. 3D Ultrastructural organization of whole Chlamydomonas reinhardtii cells studied by nanoscale soft x-ray tomography. PLoS One 2012;7: e53293.

67. Welte MA. Expanding roles for lipid droplets. Curr Biol. 2015;25: R470-481.

68. Olzmann JA, Carvalho P. Dynamics and functions of lipid droplets. Nat Rev Mol Cell Biol. 2019;20: 137-155.

69. Li FJ, He CY. Acidocalcisome is required for autophagy in Trypanosoma brucei. Autophagy. 2014;10:1978-1988.

70. Schmidt RS, Bütikofer P. Autophagy in Trypanosoma brucei: amino acid requirement and regulation during different growth phases. PLoS One. 2014;9: e93875.

71. Goldshmidt H, Matas D, Kabi A, Carmi S, Hope R, Michaeli S. Persistent ER stress induces the spliced leader RNA silencing pathway (SLS), leading to programmed cell death in Trypanosoma brucei. PLoS Pathog. 2010;6: e1000731.

72. Hope R, Ben-Mayor E, Friedman N, Voloshin K, Biswas D, Matas D, et al. Phosphorylation of the TATA-binding protein activates the spliced leader silencing pathway in Trypanosoma brucei. Sci Signal. 2014;7: ra85.

73. Morlot S, Song J, Léger-Silvestre I, Matifas A, Gadal O, Charvin G. Excessive rDNA transcription drives the disruption in nuclear homeostasis during entry into senescence in budding yeast. Cell Rep. 2019;28: 408-422.

74. Lakowicz JR. 2006. Principles of fluorescence spectroscopy. 3rd Edition, Springer, Berlin

75. Schindelin J, Arganda-Carreras I, Frise E, Kaynig V, Longair M, Pietzsch T, Preibisch S, Rueden C, Saalfeld S, Schmid B, et al. Fiji: an open-source platform for biological-image analysis. Nat Methods. 2012;9: 676-682.

76. Nunez R. DNA measurement and cell cycle analysis by flow cytometry. Curr. Issues Mol. Biol. 2001;3: 67-70.

77. Fridy PC, Li Y, Keegan S, Thompson MK, Nudelman I, Scheid JF, et al. A robust pipeline for rapid production of versatile nanobody repertoires. Nat Methods. 2014;11: 1253-1260.

78. Oberholzer M, Morand S, Kunz S, Seebeck T. A vector series for rapid PCR-mediated C-terminal in situ tagging of Trypanosoma brucei genes. Mol Biochem Parasitol. 2006;145: 117-120.

79. Sorrentino A, Nicolás J, Valcárcel R, Chichón F, Rosanes M, Avila J, et al. MISTRAL: A transmission soft X-ray microscopy beamline for cryo nano-tomography of biological samples and magnetic domains imaging. J Synchrotron Radiat. 2015;22: 1112-1117.

80. Kremer JR, Mastronarde DN, McIntosh JR. Computer visualization of three-dimensional image data using IMOD. J Struct Biol. 1996;116: 71-76.

81. Agulleiro JI, Fernandez JJ. Tomo3D 2.0--exploitation of advanced vector extensions (AVX) for 3D reconstruction. J Struct Biol. 2015;189: 147-152.

82. Belevich I, Joensuu M, Kumar D, Vihinen H, Jokitalo E. Microscopy image browser: a platform for segmentation and analysis of multidimensional datasets. PLoS Biol. 2016;14: e1002340. 
bioRxiv preprint doi: https:/doi.org/10.1101/2020.02 29.971424; this version posted February 29, 2020. The copyright holder for this preprint (which was not certified by peer review) is the author/funder, who has granted bioRxiv a license to display the preprint in perpetuity. It is made available under aCC-BY-NC-ND 4.0 International license.

\section{Figures:}
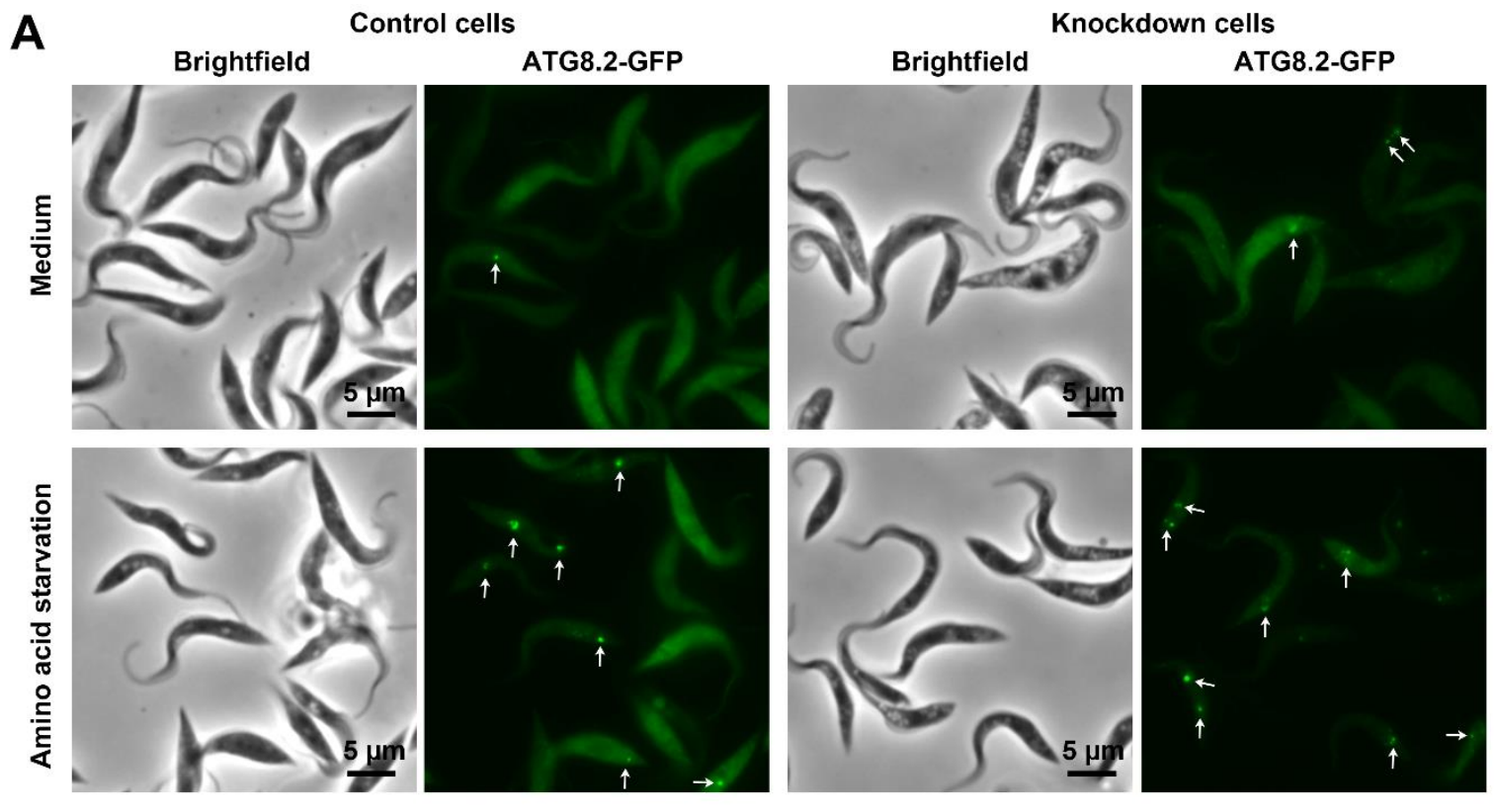

B

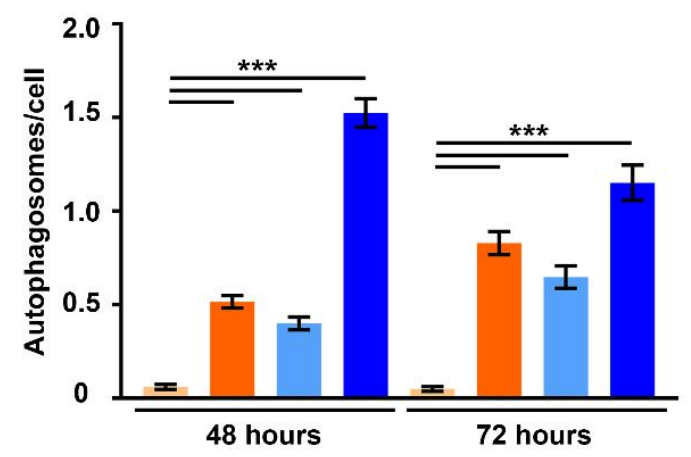

Knockdown cells - Medium

Knockdown cells - amino acid starvation

Fig 1. Analysis of autophagy response. (A) Determination of autophagosomes. Control and TbRrp44 cells were submitted to amino acid starvation in PBS containing $1 \mathrm{~g} / \mathrm{L}$ glucose or in culture medium. Left: bright field images. Right: Fluorescence of the autophagy marker ATG8.2 tagged with GFP. White arrows indicate the autophagosomes. (B) Quantification of the number of autophagosomes per cell. (C) Percentage of cells presenting autophagosomes. TbRrp44 knockdown induces autophagosomes similarly to amino acid starvation in the control cells. The ratio increases when the knockdown cells are incubated under amino acid starvation. 
A

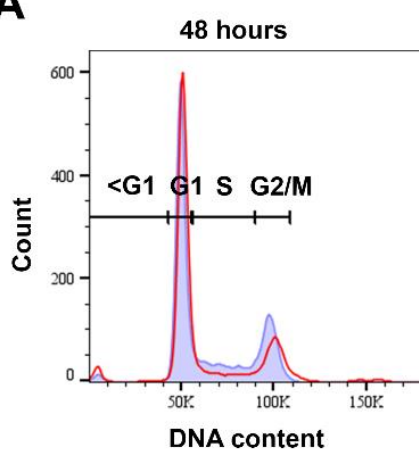

B

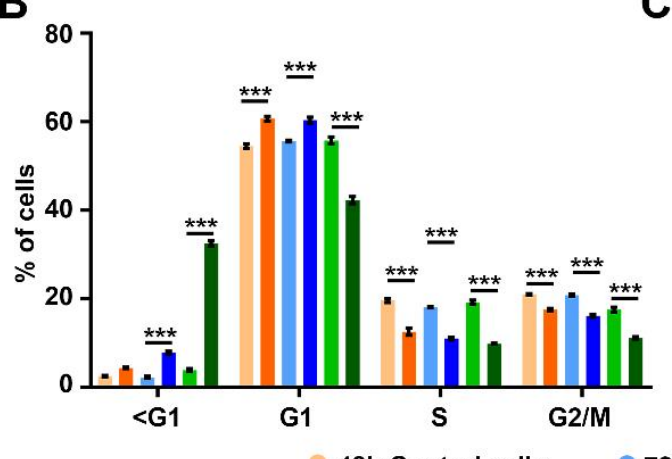

48h Control cells

$72 \mathrm{~h}$ Control cells

C
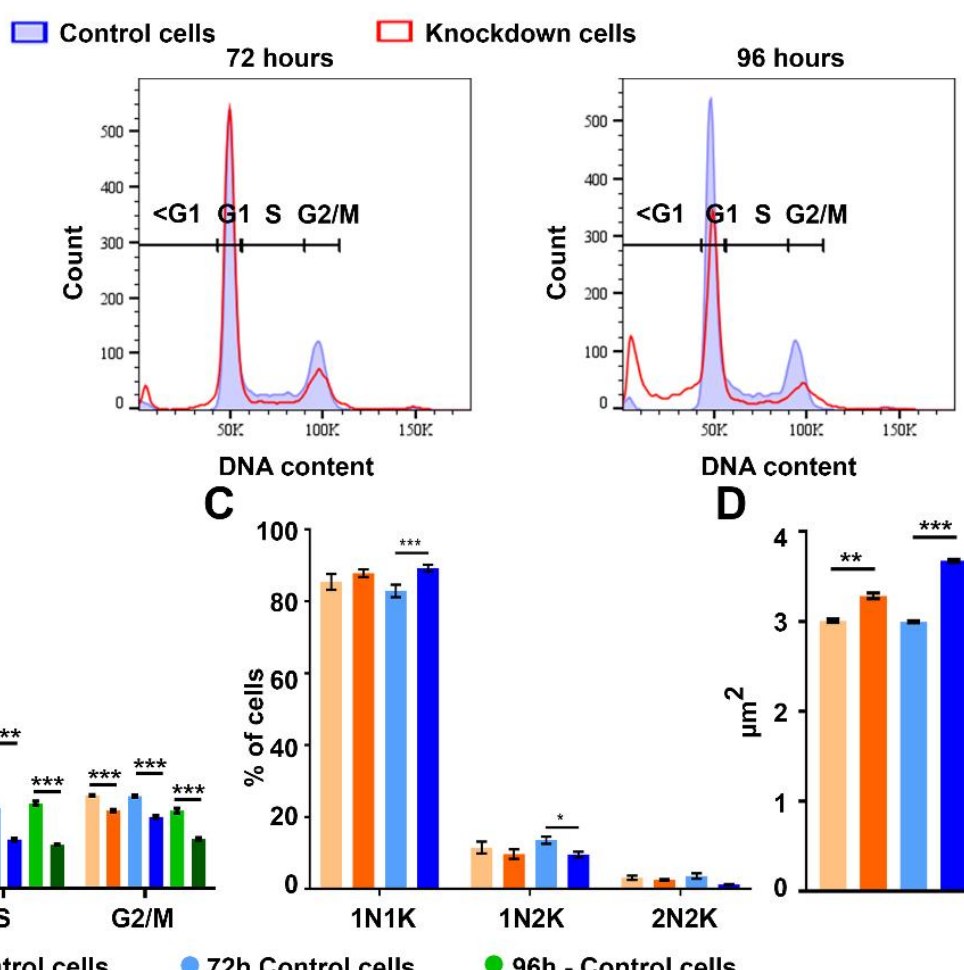

DNA content

D
$\mathbf{E}$
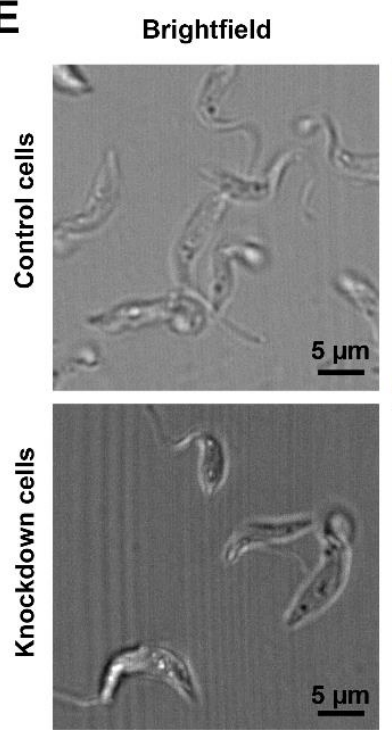

DNA
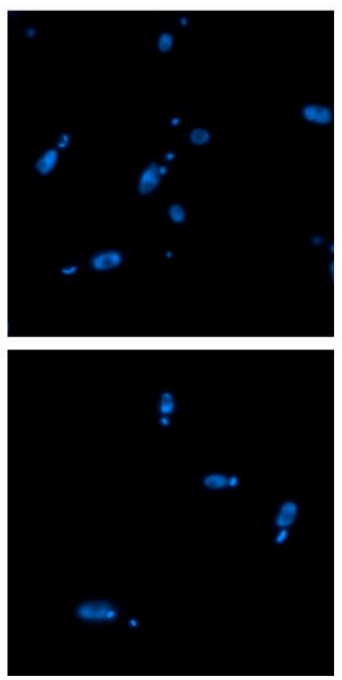

Nucleus selection (green)
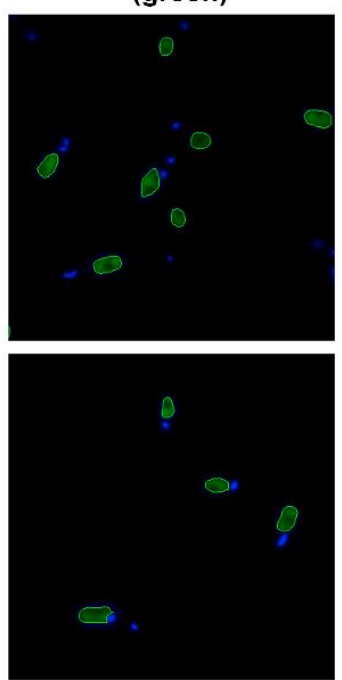

Kinetoplast selection (green)
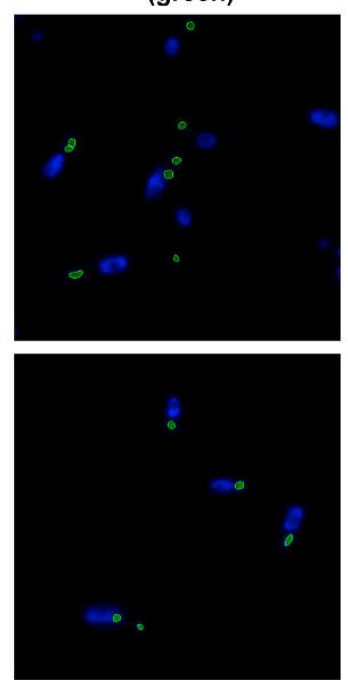

Fig 2. Changes in DNA content, nucleus/kinetoplast configuration and increase in nuclear area. For cell cycle analysis based on DNA content, cells were collected at 48,72 and $96 \mathrm{~h}$ after induction of RNAi for TbRrp44 knockdown. For quantification of nucleus/kinetoplast $(\mathrm{N} / \mathrm{K})$ ratio, cells were collected at 48 and $72 \mathrm{~h}$ after induction of RNA. (A) Cell cycle profiles determined by flow cyetry cell sorting based on DNA staining with propidium iodide. (B) Graph showing the percentage of cells per phase of the cell cycle. At the earlier times, there is a significant increase of TbRrp44-depleted cells in the G1 phase in parallel with a decrease of cells in the S and G2/M phases. At the $96 \mathrm{~h}$, there is an increase of the subG1 population with a decrease of all other stages in TbRrp44-depleted cells. This indicates that at this time, the cells start to undergo DNA damage. (C) Quantification of cells according to nucleus/kinetoplast ratio configuration. There is a small but significant increase of the $1 \mathrm{~N} / 1 \mathrm{~K}$ population, accompanied by a decrease of the $1 \mathrm{~N} / 2 \mathrm{~K}$ population in TbRrp44 knockdown cells at $72 \mathrm{~h}$ of depletion. (D) Quantification of nuclei area showing higher area average for TbRrp44-depleted cells (E) Representative images used in the analysis of N/K ratio per cell. Nuclei and kinetoplasts were stained with DAPI and selected using Harmony 4.6 software from PerkinElmer. 

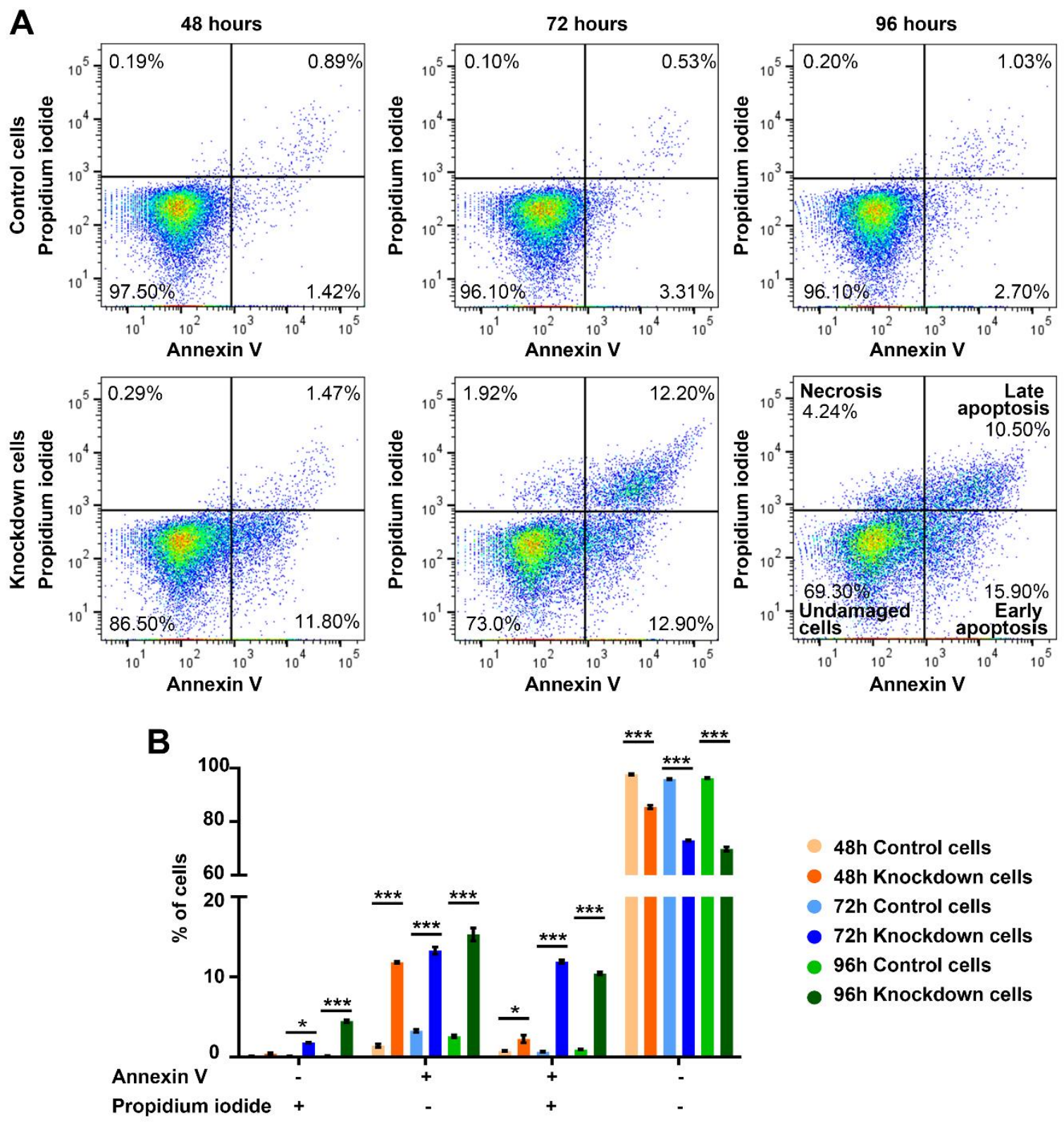

Fig 3. Quantification of pro-death and death events using membrane asymmetry and membrane damage markers. (A) Flow cytometry profiles of cells stained with annexin V-Alexa fluor 488 and propidium iodide. Samples were collected for analysis at 48,72 and 96 hours of TbRrp44 knockdown. Upper panel: control cells. Lower panel: TbRRP44 knockdown cells. (B) Graph showing the percentage of cells per category. Undamaged cells: Cells negative for staining with both markers. Necrosis: cells positive for propidium iodide. Early apoptosis: cells positive for annexin V. Late apoptosis: cells positive for both markers. The combination of cells at early and late apoptosis stages reaches $\sim 30 \%$ of the cell population starting after $72 \mathrm{~h}$ of TbRrp44 depletion indicating relatively mild damages to the cell membrane. 
bioRxiv preprint doi: https://doi.org/10.1101/2020.02.29.971424; this version posted February 29, 2020. The copyright holder for this preprint (which was not certified by peer review) is the author/funder, who has granted bioRxiv a license to display the preprint in perpetuity. It is made available under aCC-BY-NC-ND 4.0 International license.
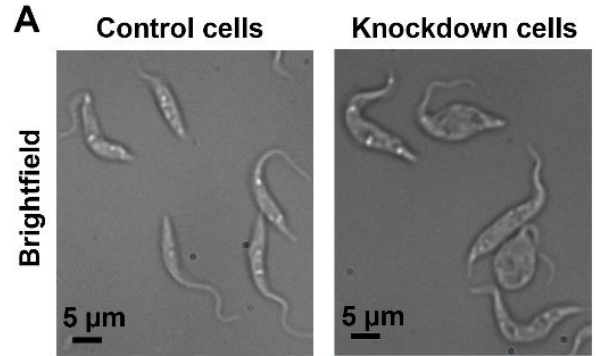

48h Control cells
48h Knockdown cells

$72 \mathrm{~h}$ Control cells

96h Control cells

B

72h Knockdown cells

@6h Knockdown cells
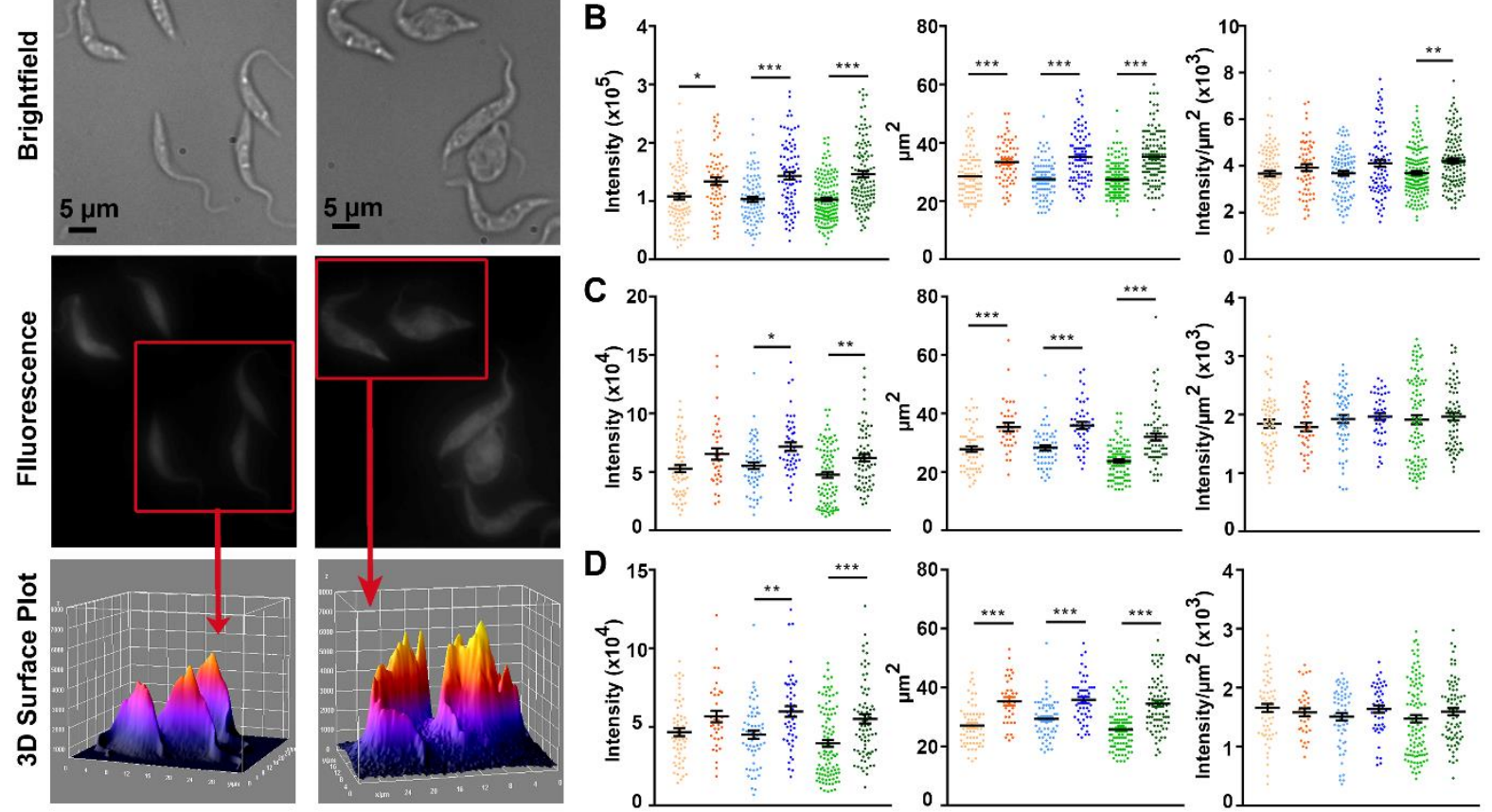

E

Control cells
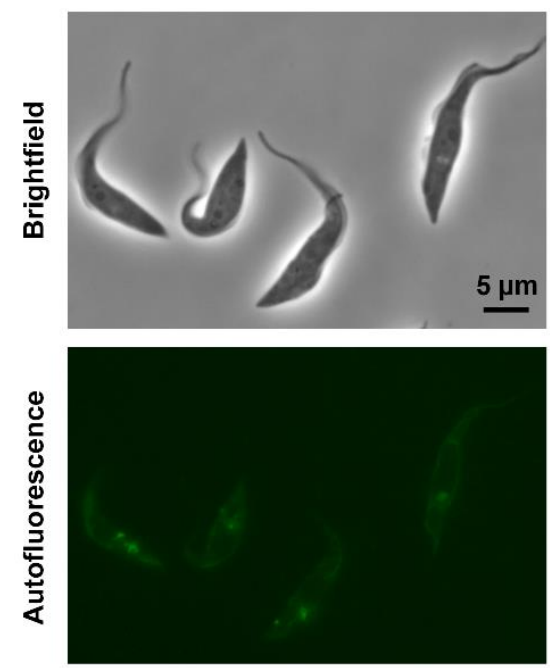

Knockdown cells
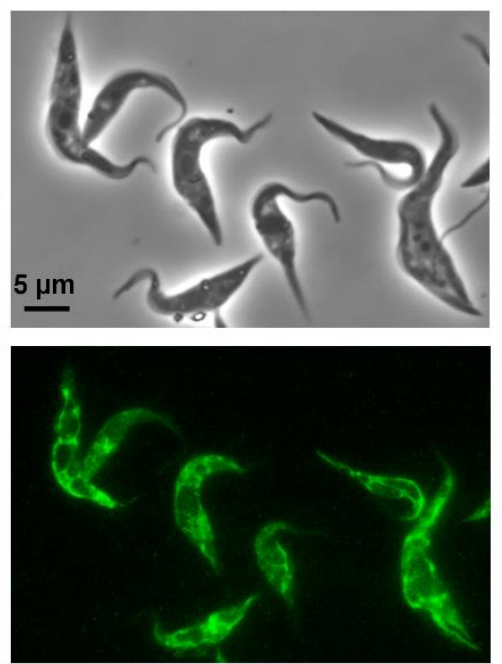

Control cells

Knockdown cells
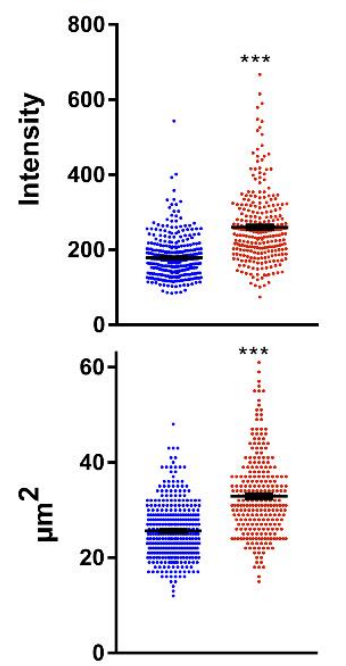

Fig 4. Analysis of autofluorescence of protein chromophores and of the metabolites NAD(P)H and FAD. (A) Differences in cells morphology and in fluorescence distribution examined with excitation at $275 \mathrm{~nm}$ and emission at $327-353 \mathrm{~nm}$. (B, C and D), Autofluorescence quantification for emission at 327-353 nm (Trp), 307-323 nm (Tyr) and 451-486 nm (NAD(P)H). Left: Graphs showing total integrated fluorescence intensity. Center: quantification of cell area. Right: ratio of fluorescence intensity per cell area. Samples were collected for analysis 48,72 and $96 \mathrm{~h}$ after induction of RNA interference for TbRrp44 knockdown. Total fluorescence and cell size are significantly increased in TbRrp44 knockdown cells. The ratio between fluorescence intensity and cell area shows a significant difference only for Trp fluorescence at $96 \mathrm{~h}$ time point. (E) Alterations in autofluorescence in the green wavelength range. Upper panel: bright field images. Lower panel: autofluorescence images with excitation at 460-500 nm and emission 512-542 nm. Left: control cells. Right: TbRrp44 knockdown cells. (F) Quantification of fluorescence intensity (upper graph) and cell area (lower graph). Knockdown of TbRrp44 leads to an increase in cell area and autofluorescence intensity in this wavelength range. 
A
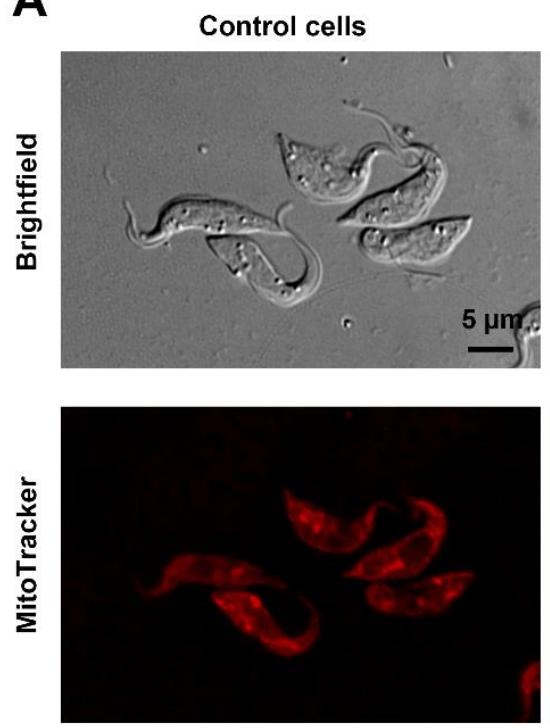

C
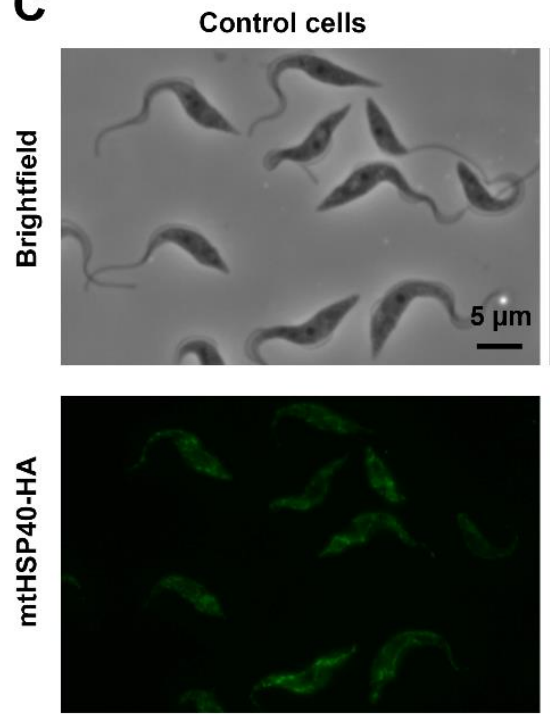

Knockdown cells
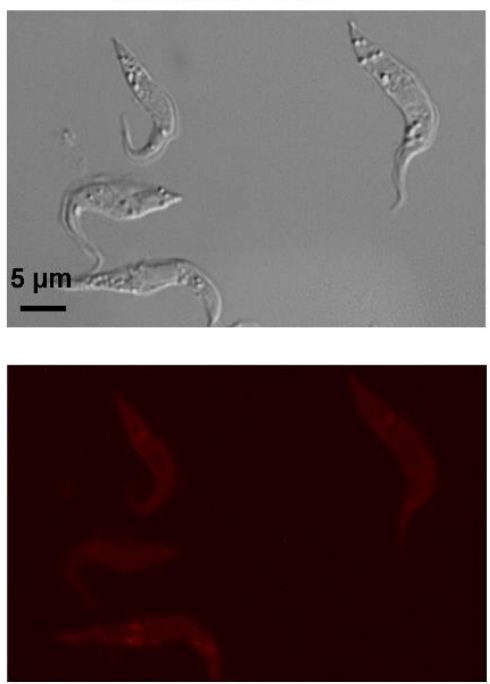

Knockdown cells
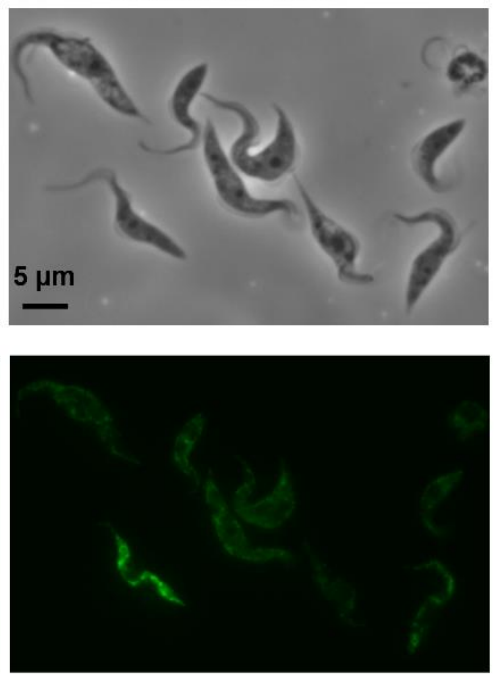

B
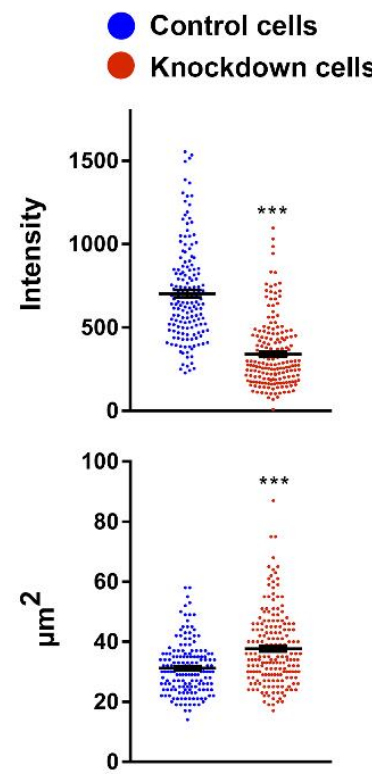

D
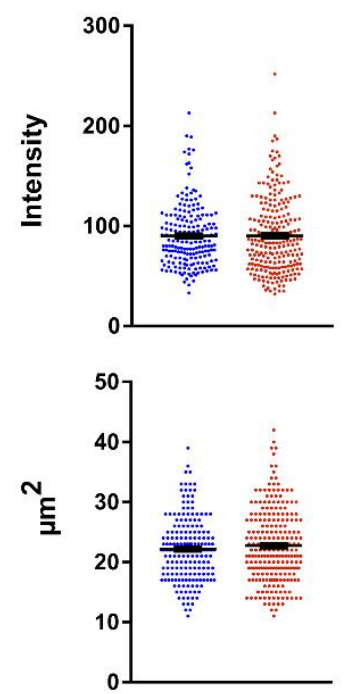

Fig 5. Analysis of mitochondrial activity and integrity. (A) Analysis of mitochondrial activity as determined by MitoTracker oxidation. Upper panel: bright field images. Lower panel: fluorescence images of cells stained with $10 \mathrm{nM}$ MitoTracker Orange CMTMROS. Images were acquired with excitation at 460-500 nm and emission 512-542 nm. Left: control cells. Right: TbRrp44 knockdown cells. (B) Determination of MitoTracker fluorescence intensity (upper graph) and cell area (lower graph). TbRrp44-deficient cells show increased cell area and reduced MitoTracker fluorescence. (C) Immunolocalization of the mitochondrial protein mtHSP40 tagged with HA. Upper panel: bright field images. Lower panel: autofluorescence images. Left: control cells. Right: TbRrp44 knockdown cells. (D) Quantification of fluorescence intensity (upper graph) and cell area (lower graph) of cells expressing mtHSP40-HA immunostained with anti-HA antibody. Similar fluorescence distribution was observed for both control and TbRrp44-depleted cells. 
bioRxiv preprint doi: https://doi org/10.1101/2020.02.29.971424 this version posted February 29, 2020. The copyright holder for this preprint (which was not certified by peer review) is the author/funder, who has granted bioRxiv a license to display the preprint in perpetuity. It is made available under aCC-BY-NC-ND 4.0 International license.

A
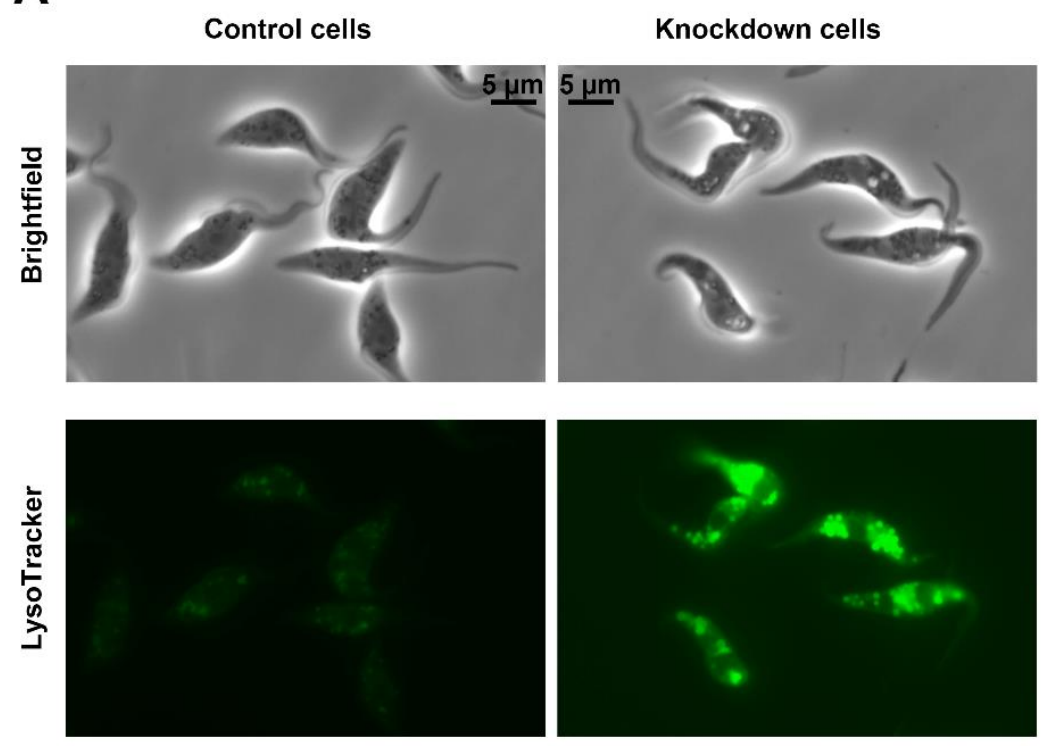

Knockdown cells

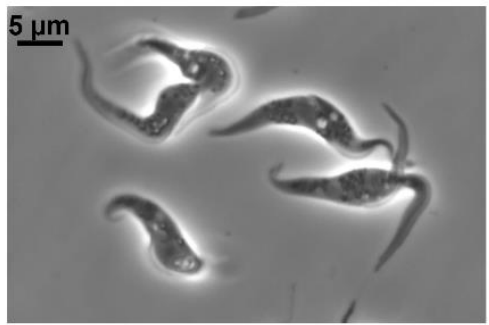

B

Control cells
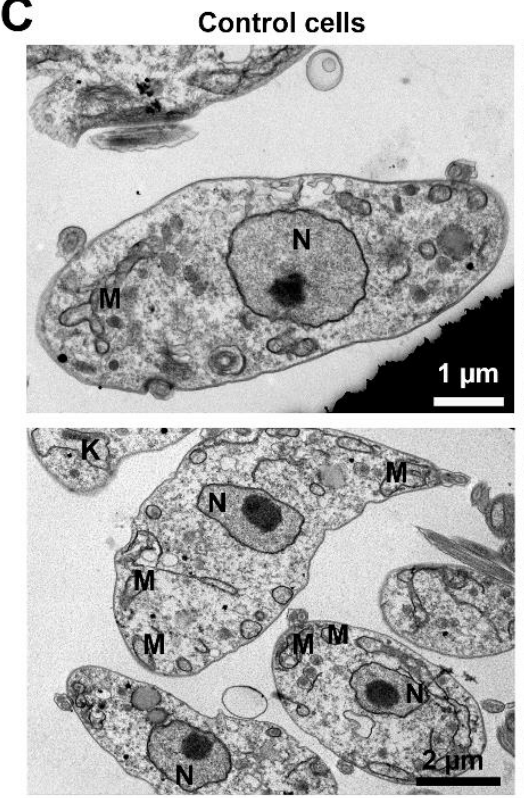

C
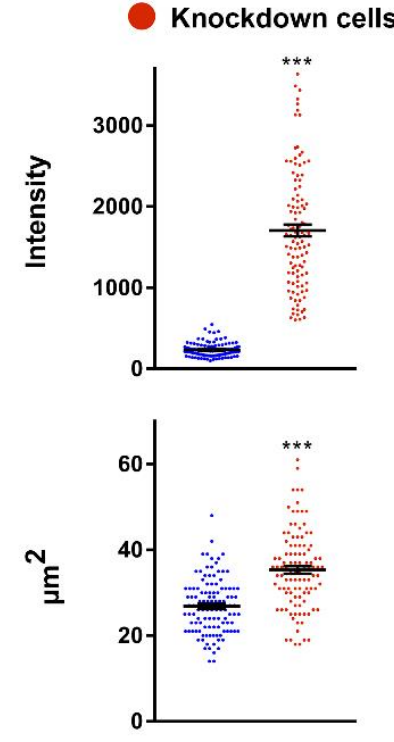
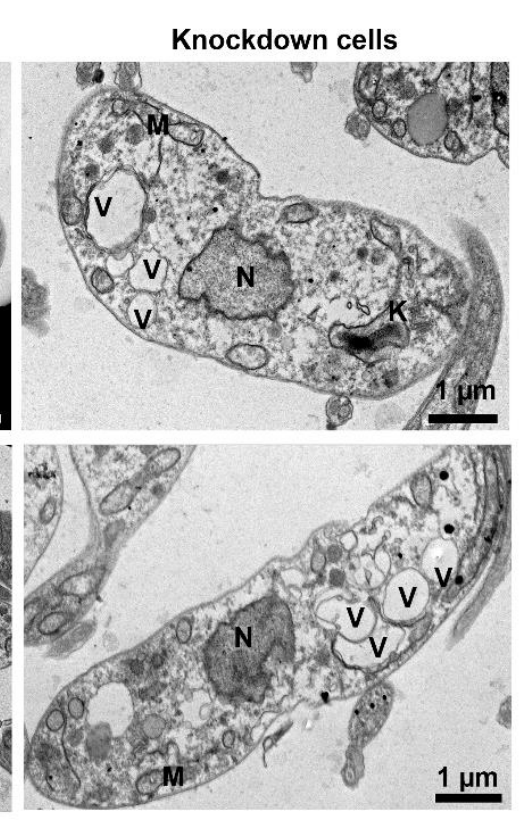

Fig 6. Evaluation of cellular vacuoles by lysotracker staining and transmission electron microscopy. (A) Determination of acidic vacuoles by labeling with LysoTracker. Images were acquired from living cells incubated with $10 \mathrm{nM}$ LysoTracker and washed with PBS before microscopic analysis. Bright field (upper panel) and LysoTracker fluorescence images (lower panel) of control cells (left panel and TbRrp44 knockdown cells (right panel). (B) Quantification of LysoTracker fluorescence intensity (upper graph) and cell area (lower graph). TbRrp44 knockdown cells show increase of cell area, over six-fold higher fluorescence intensity and larger Lysotracker-stained vacuoles. (C) Transmission electron microscopy analysis of control $T$. brucei cells (left panels) and TbRrp44 knockdown cells (right panels). TbRrp44 knockdown cells show large vacuoles (V) that are not present in control cells. Nuclei $(N)$, chromatin, kinetoplast $(K)$, lipid droplets $(L)$, mitochondria $(M)$ and flagellum $(F)$ show a regular conformation. Autophagosomes are not detected probably due to the low number per cell. 
A
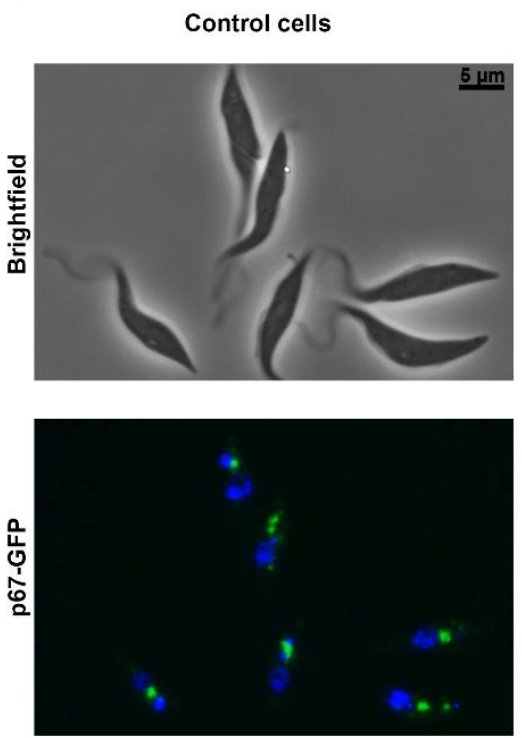

C
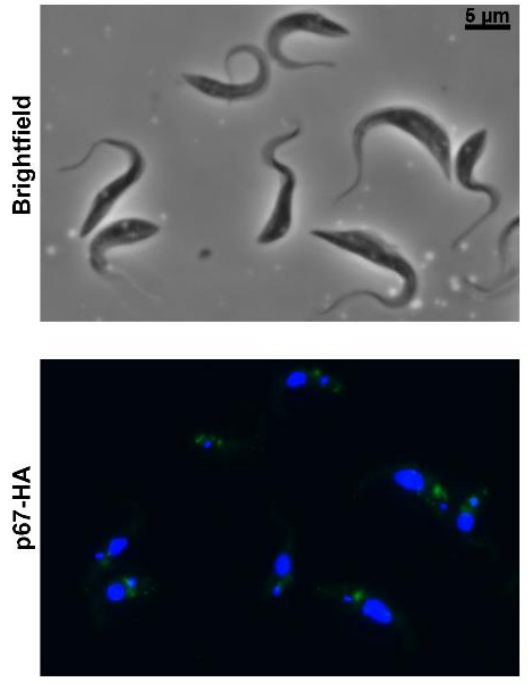

Knockdown cells
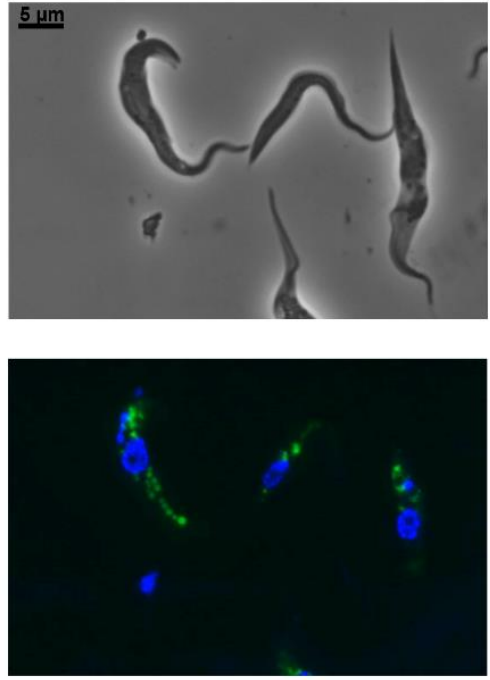

Knockdown cells
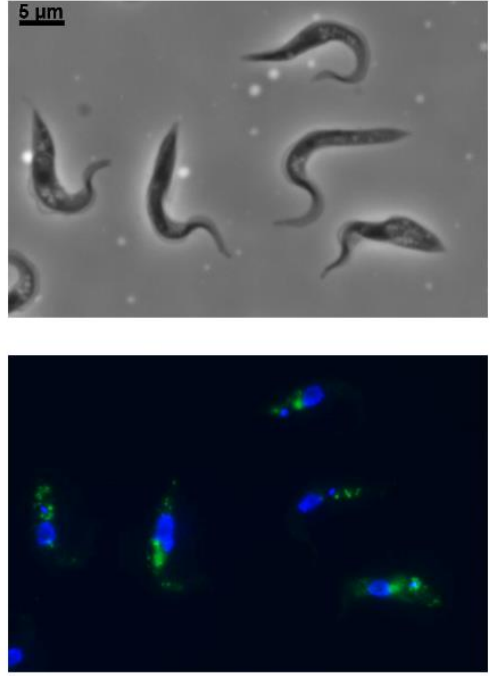

B
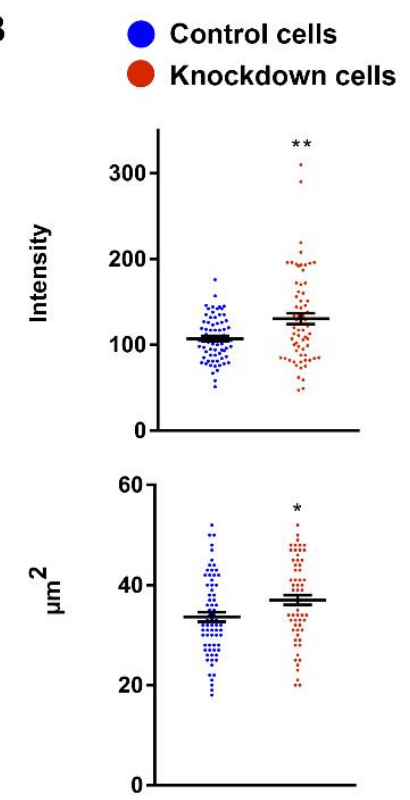

D
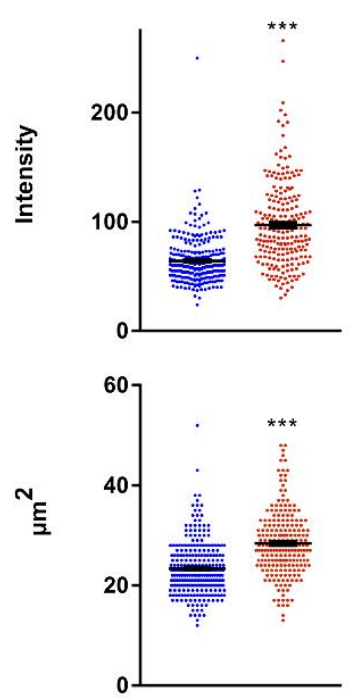

Fig 7. Evaluation of lysosomes using the lysosomal protein marker p67. (A) Localization of the lysosomal protein marker p67 tagged with GFP. (B) Quantification of fluorescence intensity (upper graph) and cell area (lower graph) of cells expressing p67-GFP. A significant increase in fluorescence intensity and cell area in TbRrp44 knockdown cells was observed for p67-GFP. (C) Immunolocalization of the lysosomal protein p67 tagged with HA. (D) Quantification of fluorescence intensity (upper graph) and cell area (lower graph) of cells expressing p67-HA immunostained with anti-HA antibody. A significant increase in fluorescence intensity and cell area was observed for p67-HA in TbRrp44 knockdown cells. This analysis shows an increase of lysosome-derived structures in TbRrp44 knockdown cells. 


\section{Control cells}
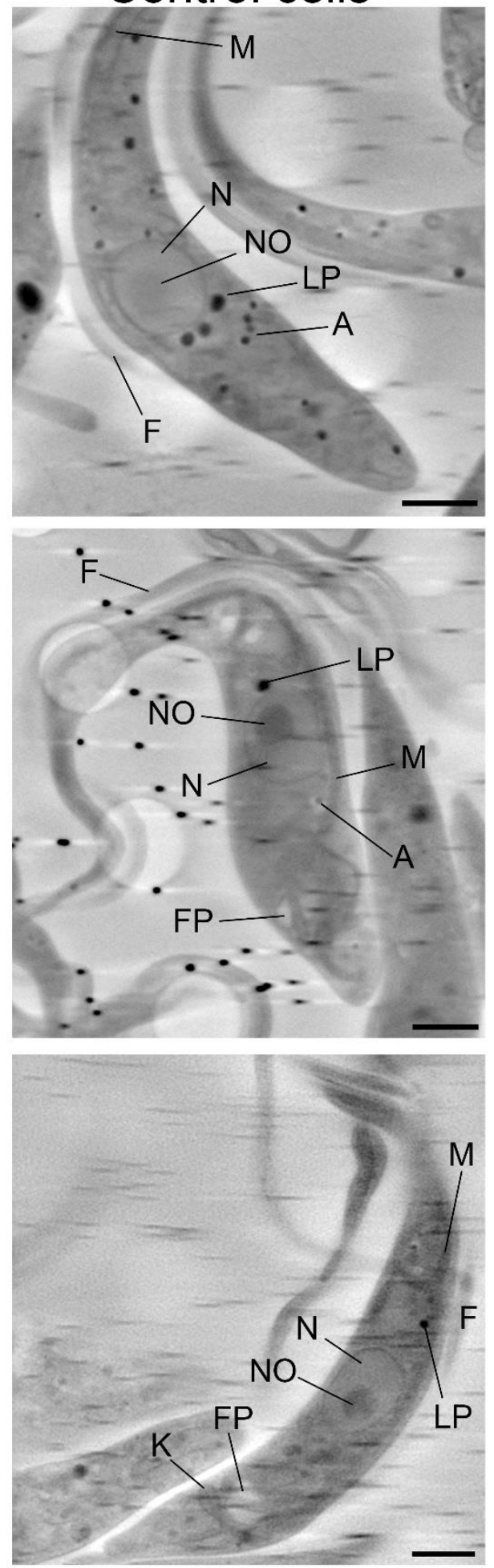

Knockdown cells
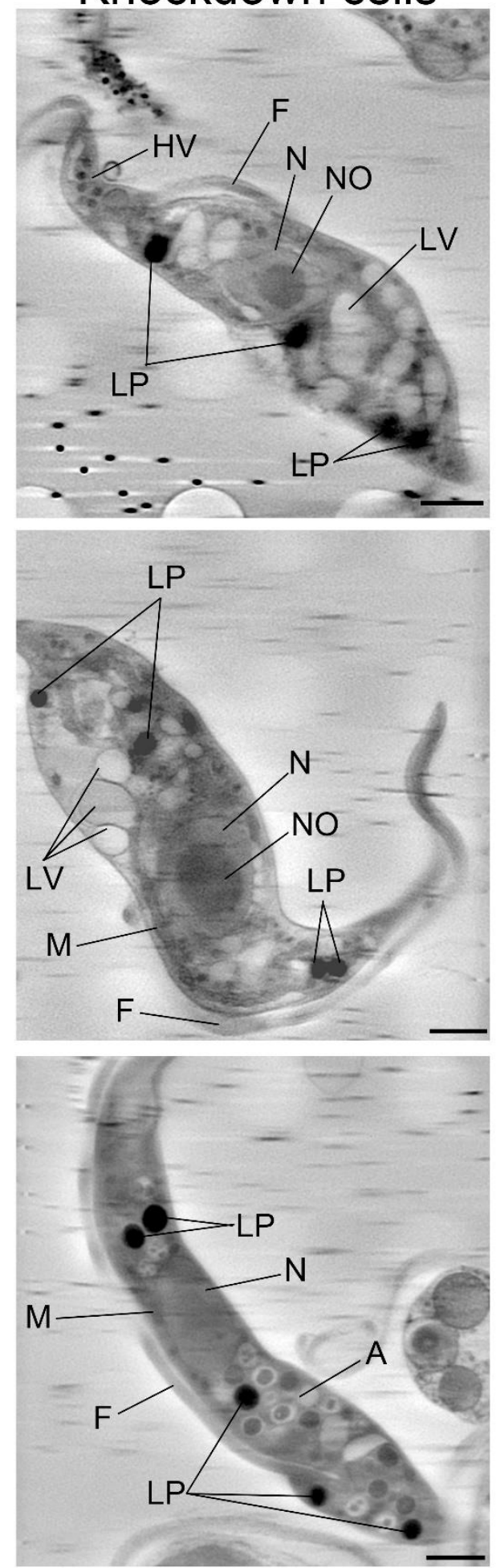

Fig 8. Cryo soft X-ray tomography volume slices of control and TbRrp44 knockdown cells. Control cells are shown in the left panels. The cells shown in the right panels were collected at 72 hours after induction of RNA interference against the TbRrp44 mRNA. Letters indicate the organelles identified. N: nucleus; NO: nucleolus; FP: flagellar pocket; F: flagellum; LP: lipid droplets; HV: high absorption vesicles; A: acidocalcisomes; LV: low absorption vacuoles; M: mitochondria. Scale bar, $1.5 \mu \mathrm{m}$. 
bioRxiv preprint doi: https://doi org/10.1101/2020.02 29.971424 this version posted February 29,2020 . The copyright holder for this preprint (which was not certified by peer review) is the author/funder, who has granted bioRxiv a license to display the preprint in perpetuity. It is made available under aCC-BY-NC-ND 4.0 International license.
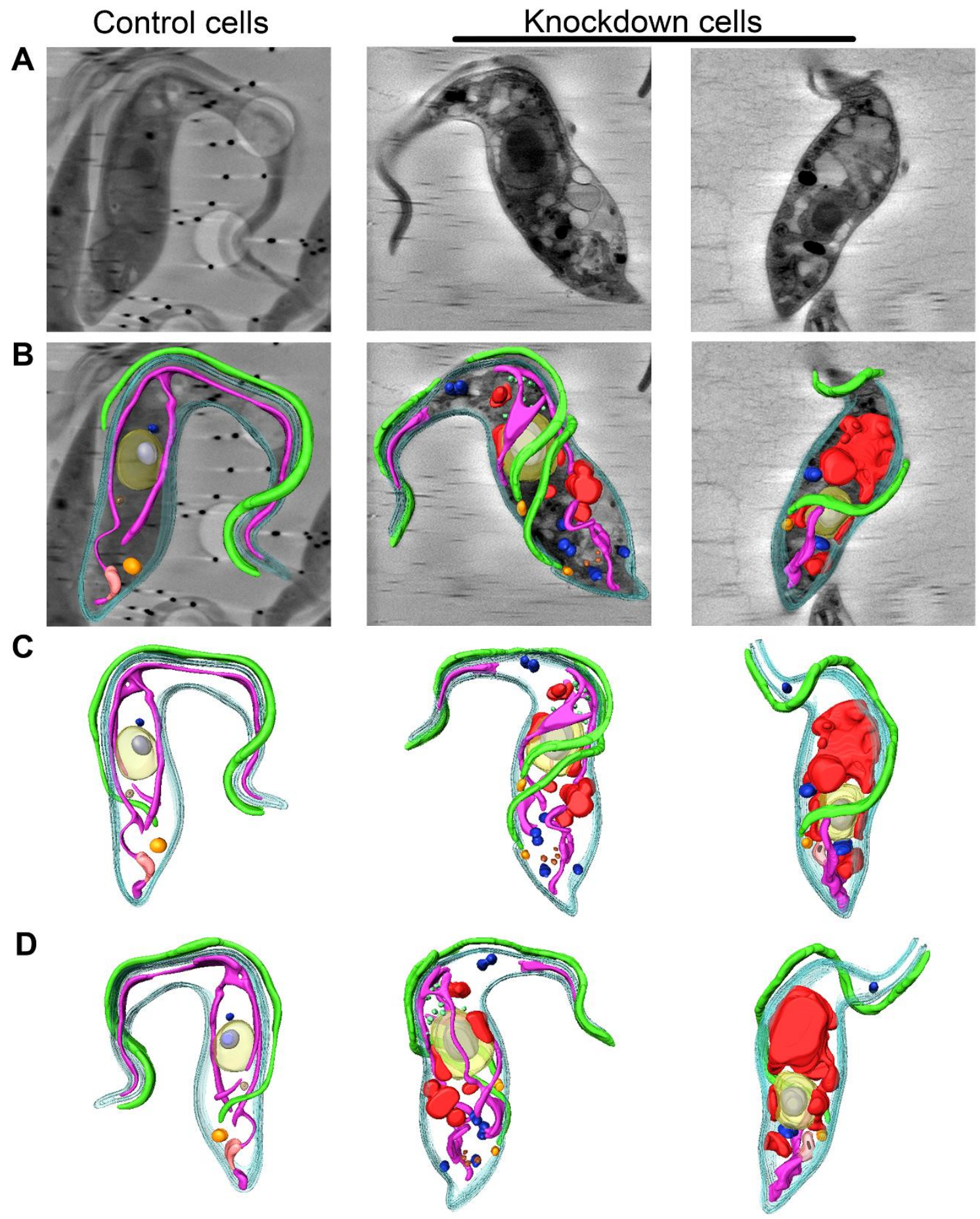

Fig 9. Segmentation of the 3D cryo-SXT reconstructions of T. brucei cells. A control cell is shown in the left panel. The center and right panels show cells after 72 hours of TbRrp44 depletion with different stages of vacuolation. The cell on the right shows a single large vacuole taking most part of the anterior pole. (A) Original volume slices before segmentation. (B) Organelle segmentation shown on a volume slice of control and knockdown cells. (C-D) Segmentation of cell structures with $180^{\circ}$ rotation. Cyan: membrane; yellow: nucleus; light grey: nucleolus; green: flagellum; orange: flagellar pocket; purple: mitochondrion; pink: kinetoplast; brown: acidocalcisome; blue: lipid droplets; red: low absorption vacuoles; light green: high absorption vesicles. 
bioRxiv preprint doi: https://doi.org/10.1101/2020.02 29.971424; this version posted February 29, 2020. The copyright holder for this preprint (which was not certified by peer review) is the author/funder, who has granted bioRxiv a license to display the preprint in perpetuity. It is made available under aCC-BY-NC-ND 4.0 International license.

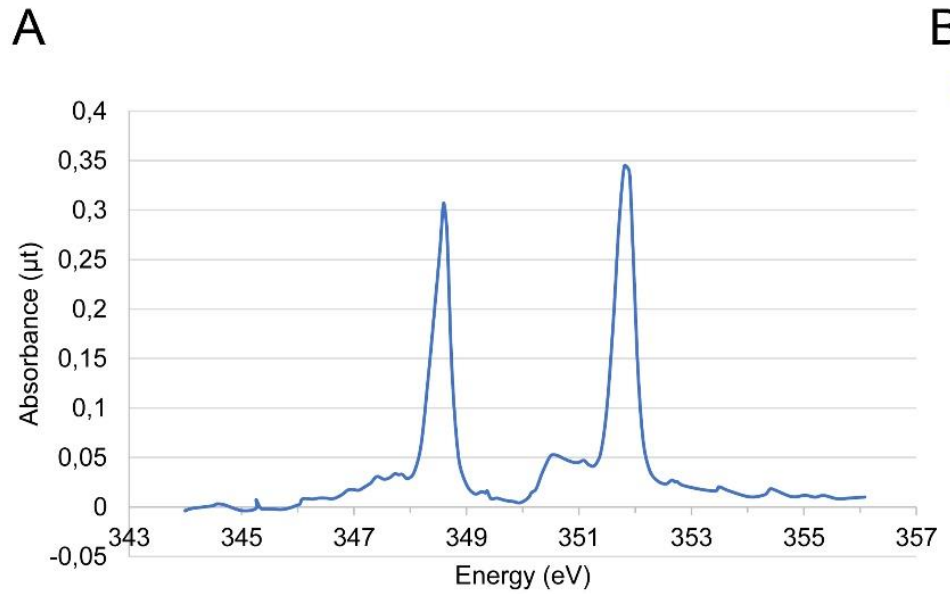

B
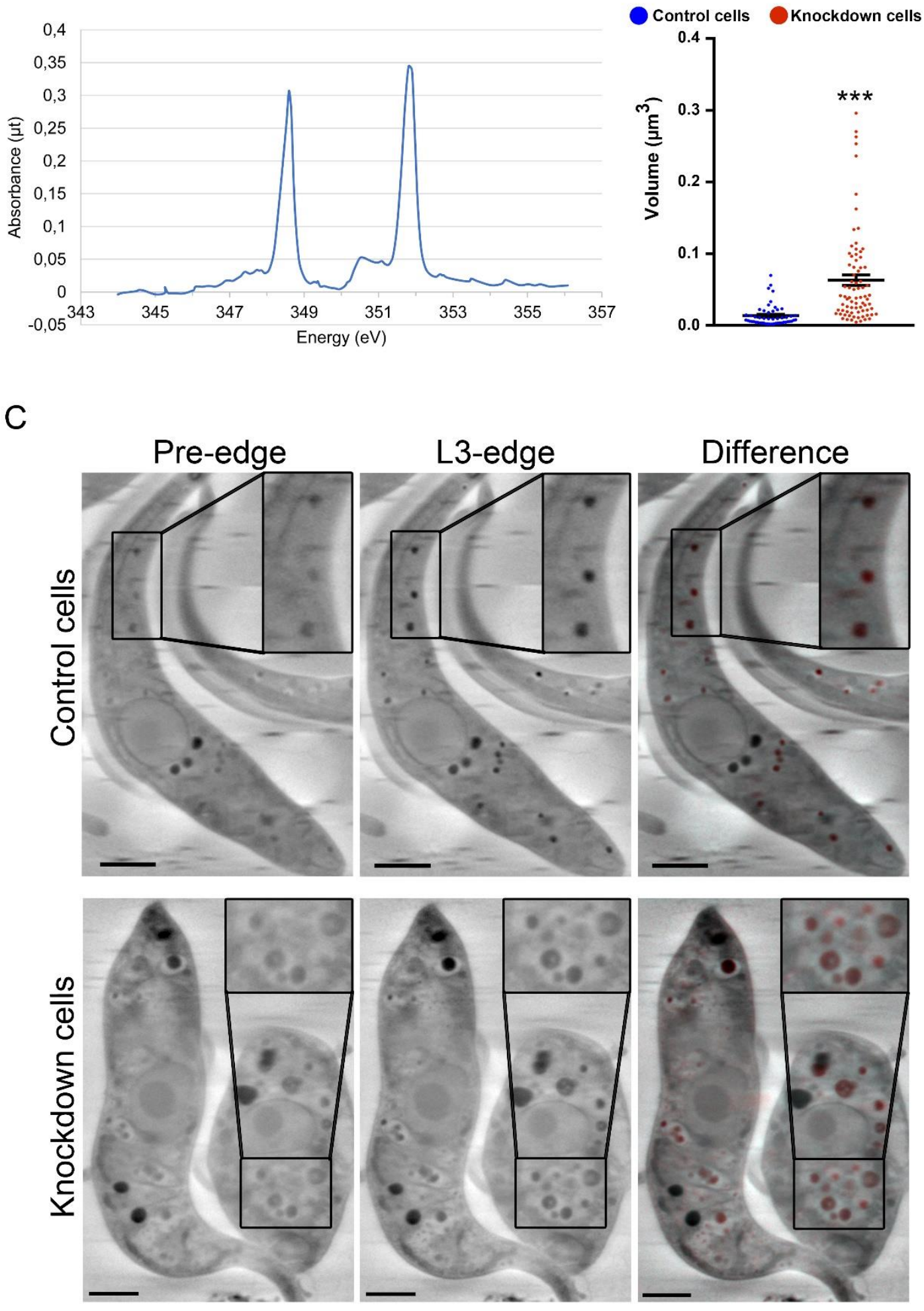

Fig 10. Cryo spectromicroscopy at the Ca L-edges. (A) XANES spectrum of the calcium absorbance found in the Ca-containing vesicles showing the L3- and L2-edges. The spectrum corresponds to $\mathrm{Ca}$ in solution as in [57]. (B) Quantification of the volume of calcium-containing vesicles from three cryo-SXT reconstructed cells. (C) Subcellular localization of calcium. Images of control and knockdown cells collected at the calcium pre-edge (left panel) and L3-edge (center panel). The calcium-containing organelles evidenced by the difference between the L3-edge and pre-edge images are highlighted in red over an image of the same cell (right panel). Scale bar, $1.5 \mu \mathrm{m}$. 
bioRxiv preprint doi: https://doi.org/10.1101/2020.02.29.971424; this version posted February 29, 2020. The copyright holder for this preprint (which was not certified by peer review) is the author/funder, who has granted bioRxiv a license to display the preprint in perpetuity. It is made available under aCC-BY-NC-ND 4.0 International license.

A
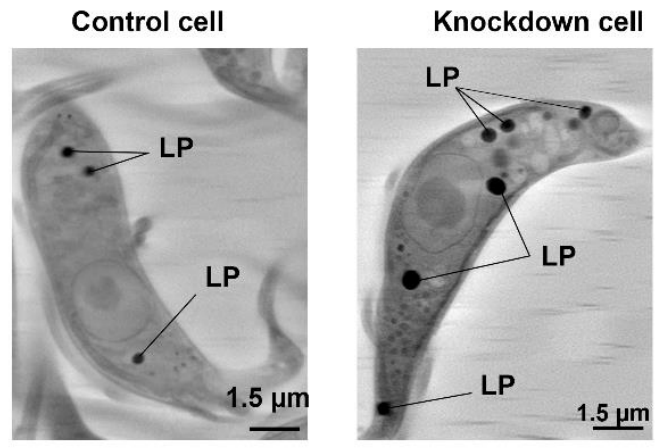

C
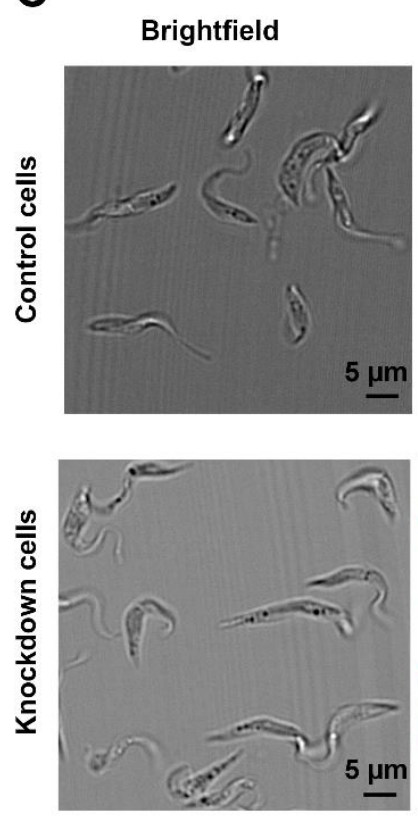

B

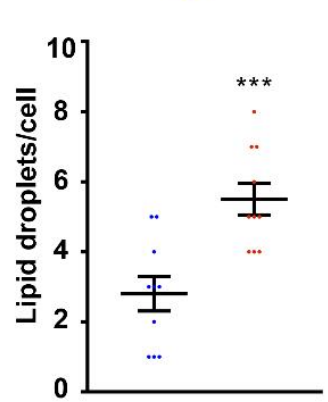

Knockdown cells

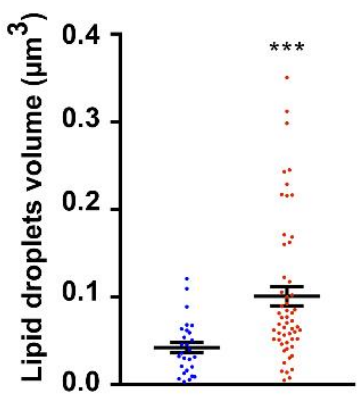

D
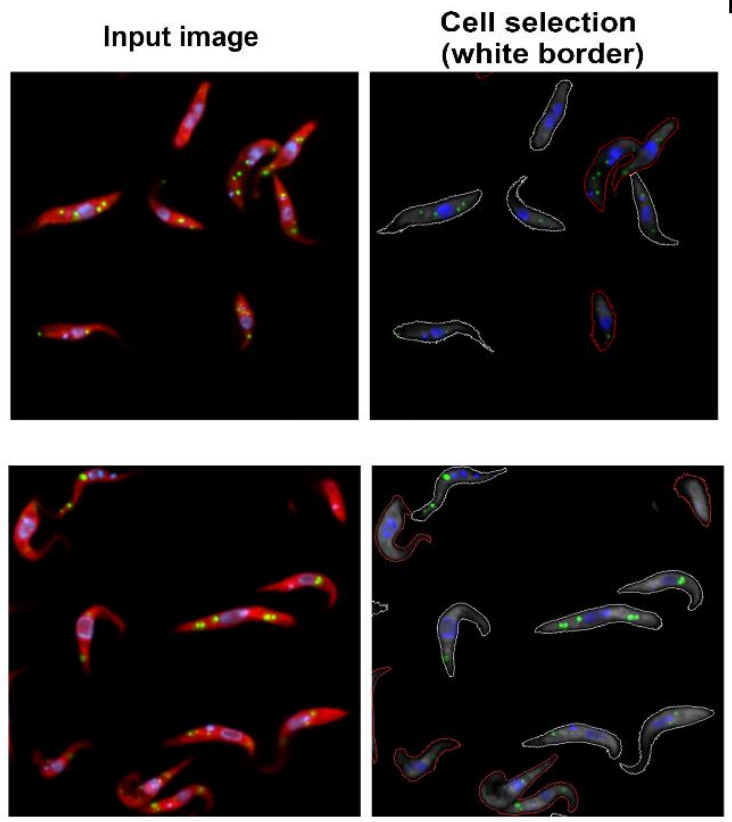

D $48 \mathrm{~h}$ Control cells

48h Knockdown cells - 72h Control cells

- 72h Knockdown cells
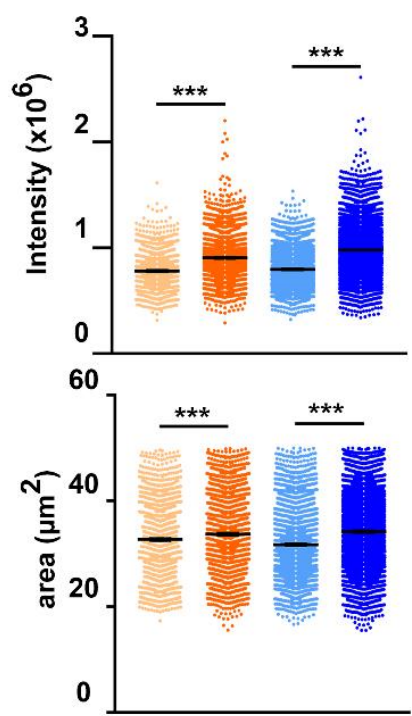

Fig 11. T. brucei TbRrp44-depleted cells accumulate a higher number and larger lipid droplets. (A) Representative cryo soft X-ray tomography volume slices of control (left) and TbRrp44 knockdown (right) cells. Lipid droplets are indicated (LP). (B) Number per cell (left) and volumes (right) of lipid droplet quantification from cryo-SXT reconstructed cells. A total of 10 cells was used in this analysis. (C) Representative images of the cells used for quantification of lipid droplets stained with Nile Red. Left: bright field images. Center: cells imaged in red, nuclei and kinetoplasts in blue and lipid droplets in green. Green and red fluorescence are both from Nile Red. Right: Cell contour for quantification of cell area defined based on the red fluorescence. (D) Quantification of the green fluorescent intensity of cells stained with Nile Red. Samples were collected at 48 and 72 hours after induction of RNA interference to deplete TbRrp44. TbRrp44 knockdown cells show a significant increase in the fluorescence signal (upper graph). The graph on the bottom shows the quantification of the cell size. 


\section{Supplemental materials}

\section{Supplemental figures}
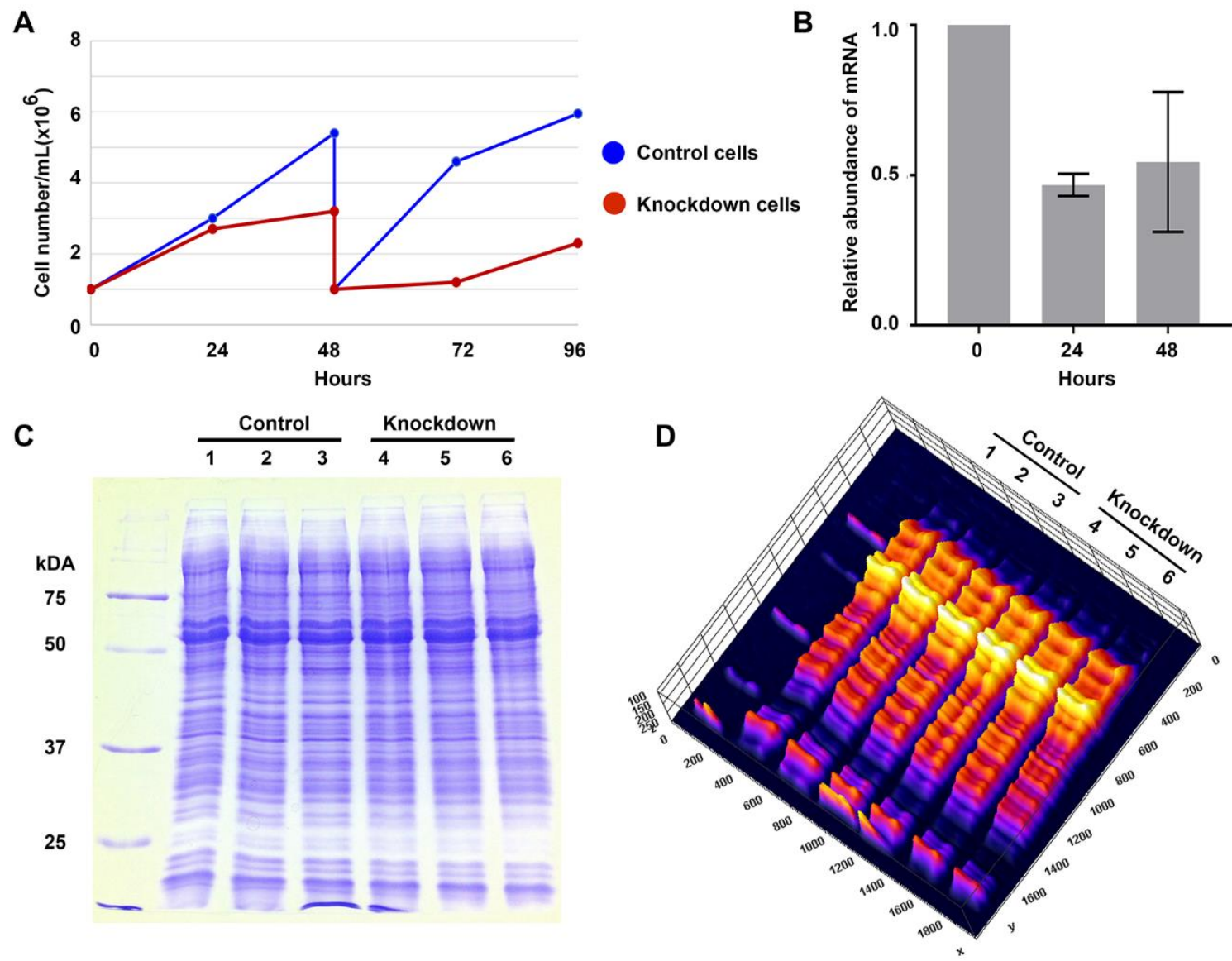

S1 Fig. Effect of TbRrp44 depletion on cell proliferation and protein content. (A) Growth curves of $T$. brucei conditional strain for TbRrp44. The blue line indicates the growth rate of control cultures. The red line indicates the growth rate of cells in which RNA interference was induced for knockdown of TbRRP44. At the time points of 48 hours the cell number were diluted down to $1 \times 10^{6} \mathrm{cells} / \mathrm{mL}$ to keep cell density in optimal range for $T$. brucei cultures. (B) Analysis of TbRRP44 mRNA levels by quantitative RT-PCR. The normalized level of mRNA was set to 1 for control cells (time 0 ) and the graphs show the reduction of mRNA levels relative to time 0 at the indicated times. The results shown are averages from three independent experiments each performed with triplicates. (C) Total protein extracts of control and knockdown cells analyzed by SDS-PAGE and stained with Coomassie blue. Extract were prepared from three separate cultures. The same number of cells per volume was used $\left(1.83 \times 10^{8}\right.$ control cells lysed in $261 \mu \mathrm{L}$ of $0.05 \%$ SDS v/v; $2.52 \times 10^{8}$ TbRrp44 knockdown cells, with RNA interference induced for 72 $\mathrm{h}$, lysed in $317 \mu \mathrm{L}$ of $0.05 \%$ SDS $\mathrm{v} / \mathrm{v}$ ). $10 \mu \mathrm{L}$ of each extract were analyzed in gel and stained with Coomassie blue. Left lane, molecular mass marker; lanes 1-3, extracts from control cells; lanes 4-6, extracts from TbRrp44 knockdown cells. (D) 3D surface plot of the gel showed in C generated using FIJI software (Schindelin et al., 2012). Similar amounts of proteins are observed in both control and TbRRP44 knockdown cells. 
bioRxiv preprint doi: https:/doi org/10.1101/2020.02 29 971424 : this version posted February 29, 2020. The copyright holder for this preprint (which was not certified by peer review) is the author/funder, who has granted bioRxiv a license to display the preprint in perpetuity. It is made available under aCC-BY-NC-ND 4.0 International license.
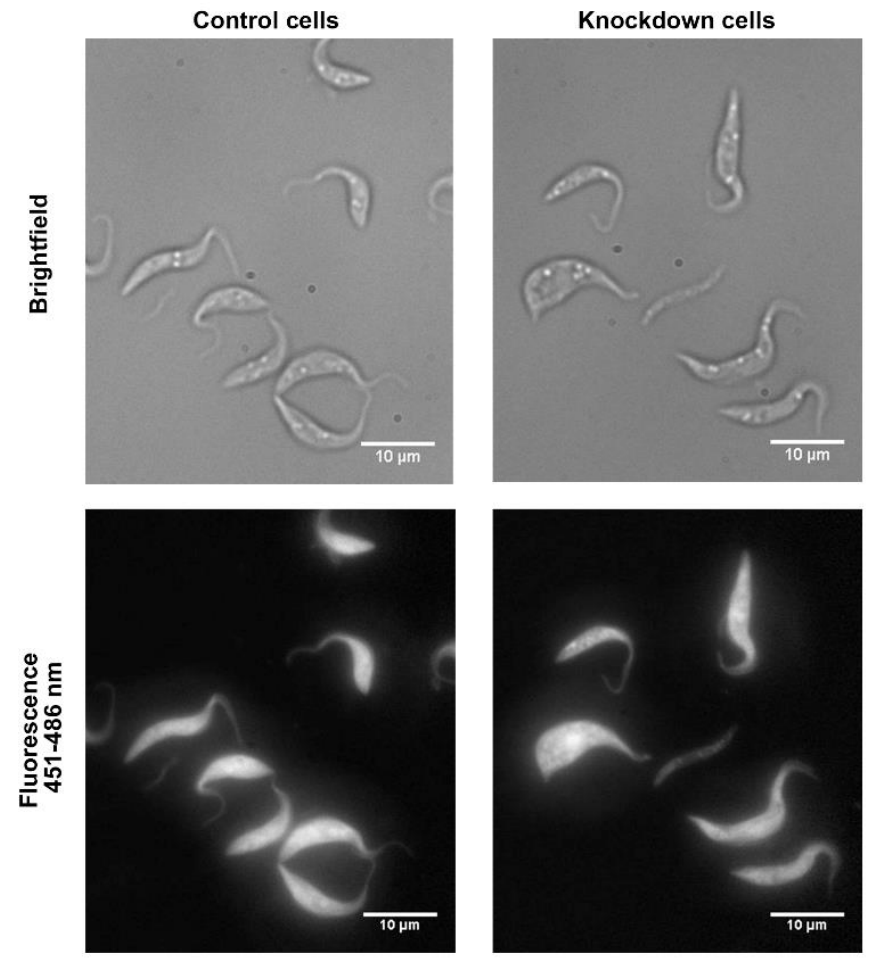

S2 Fig. Evaluation of fluorescence distribution in the 451-486 $\mathrm{nm}$ [NAD(P)H] emission range in T. brucei cells depleted of TbRRP44 for 72 hours. The upper panel shows bright field images of control cells (left) and knockdown cells (right). The lower panel shows autofluorescence images acquired in the in the 451-486 nm emission range of control (left) and knockdown cells (right). 
A
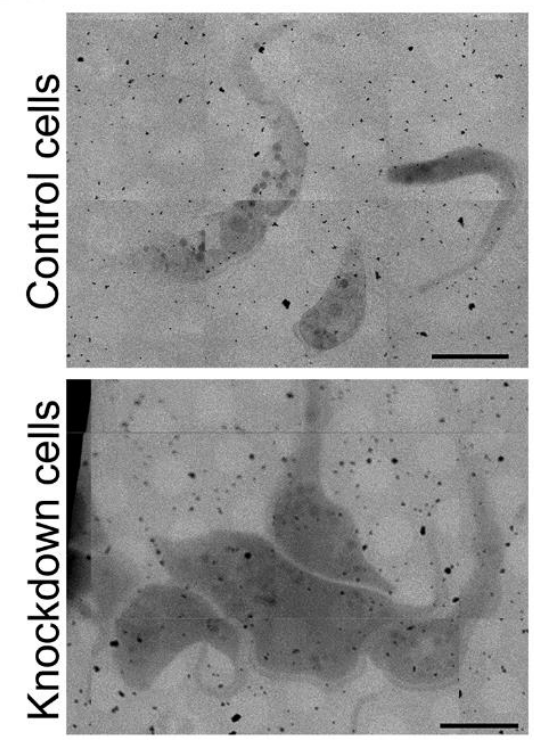

B
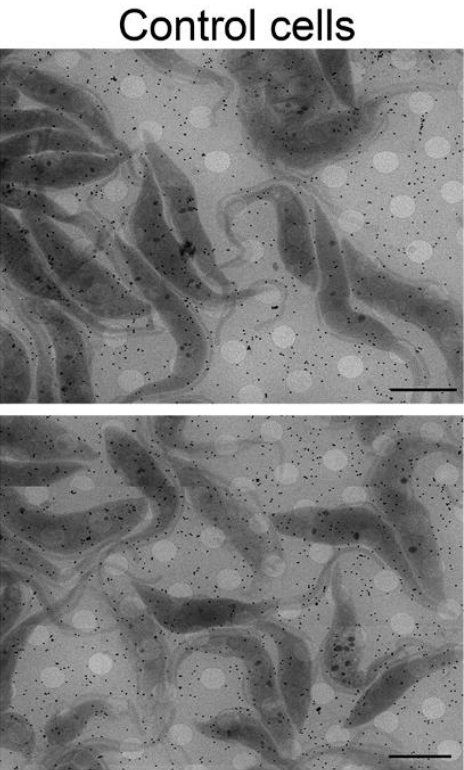

Knockdown cells
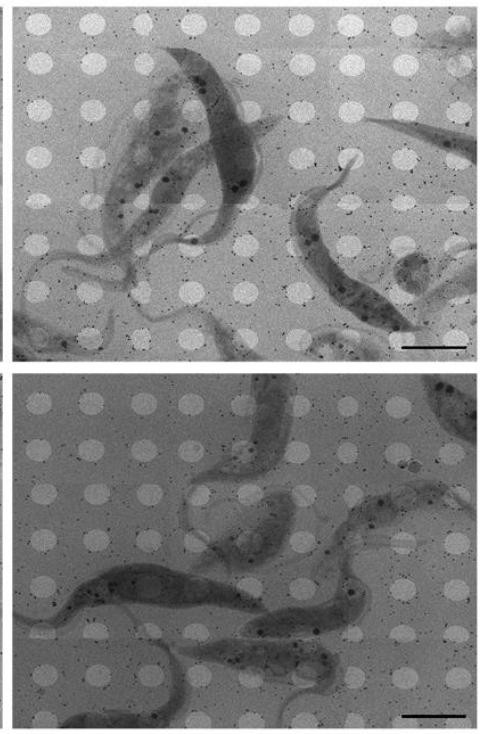

C

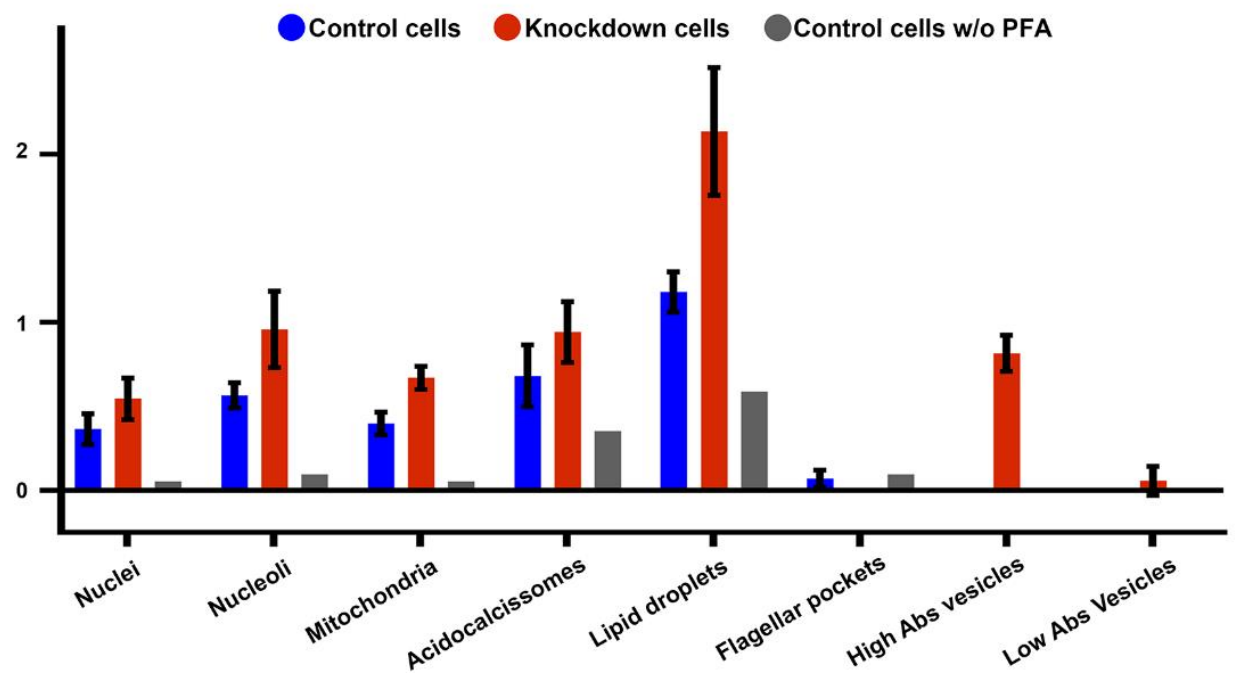

S3 Fig. Effect of PFA on the preservation of morphology and increase of linear absorption coefficient. (A) Representative X-ray mosaics of projections of cells not fixed with PFA. (B) Representative X-ray mosaics of projections used to select cells for cryo soft X-ray tomography. Scale bar, $5 \mu \mathrm{m}$. (C) Comparison of average linear absorption coefficient (LAC) for organelles in the T. brucei cells. Four to six tomograms (depending on the analyzed organelle) of PFA-fixed control and knockdown cells were used for quantification. Despite the difficulty to work with unfixed cell, we managed to reconstruct the three-dimensional (3D) structure of two control cells that have not been submitted to the PFA treatment. For comparison, average LAC for organelles of non-fixed control cells based on two tomograms are also shown. Due to the low number, no error bars are shown for them. Although relatively short, the PFA treatment appears to have a high impact on LAC values. In PFA-treated control cells, the LAC of nuclei, nucleoli and mitochondria was approximately 5 times higher, while lipid droplets and acidocalcisomes showed LAC $\sim 2$ times higher relative to the LAC of untreated cells. In TbRrp44 knockdown cells, the LAC of these organelles was significantly higher than in control cells. However, it is not possible to know if this is a phenotype caused by TbRrp44 depletion, corresponding to a real increase in the LAC value or, if it is an artifact caused by PFA fixation. 

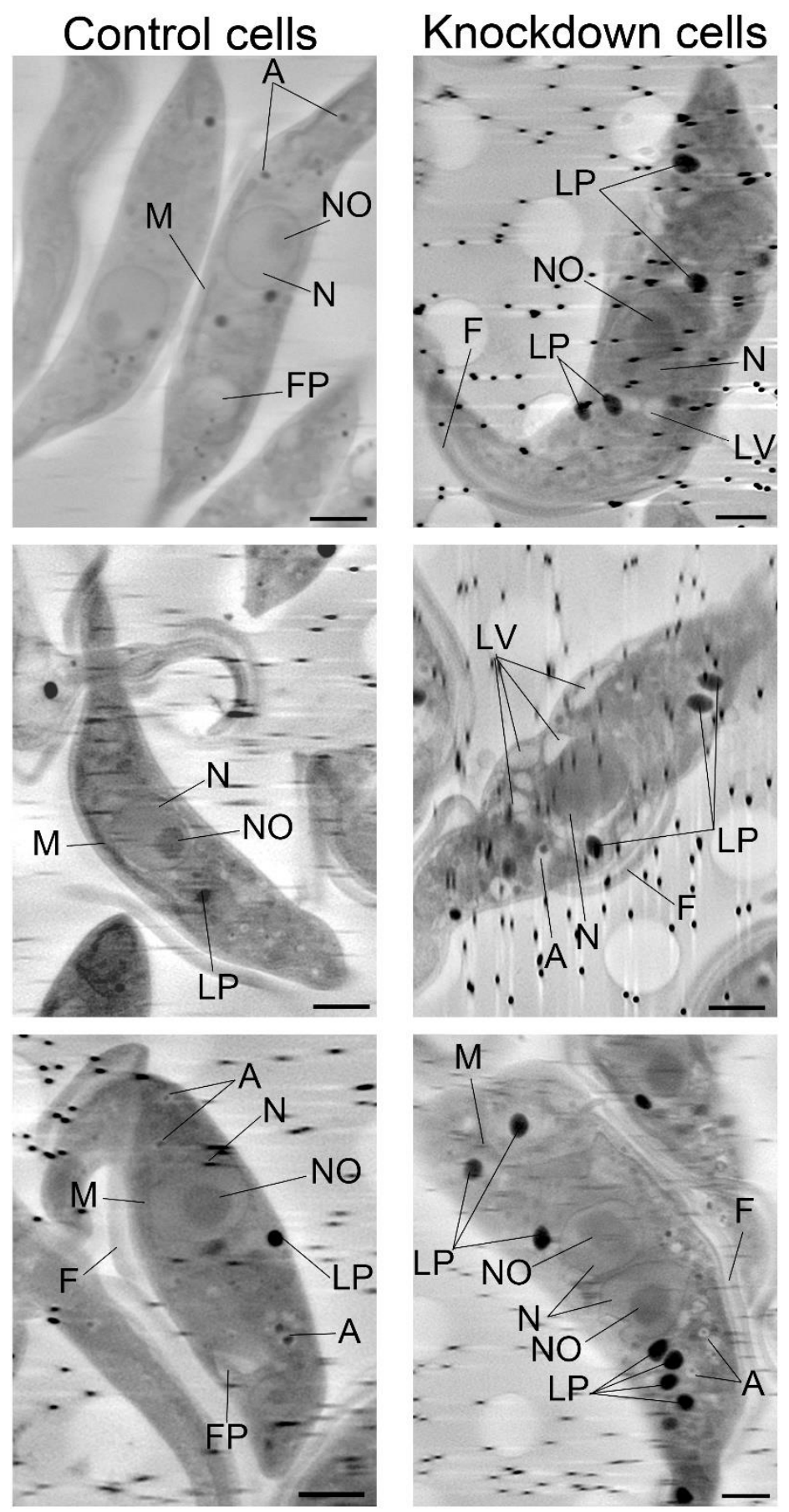

S4 Fig. Cryo soft X-ray tomography volume slices of control (left panels) and of TbRRP44 knockdown cells (right panels) at $\mathbf{4 8}$ hours after induction of RNA interference. Letters indicate the organelles identified. N: nucleus; NO: nucleolus; FP: flagellar pocket; F: flagellum; LP: lipid droplets; HV: high absorption vacuoles; A: acidocalcisomes; LV: low absorption vacuoles; M: mitochondria. Scale bar, $1.5 \mu \mathrm{m}$. The cell on the bottom right is undergoing division and shows two nuclei. 


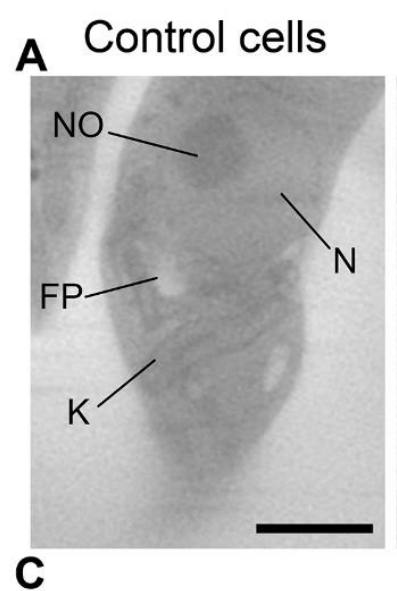

Knockdown cells
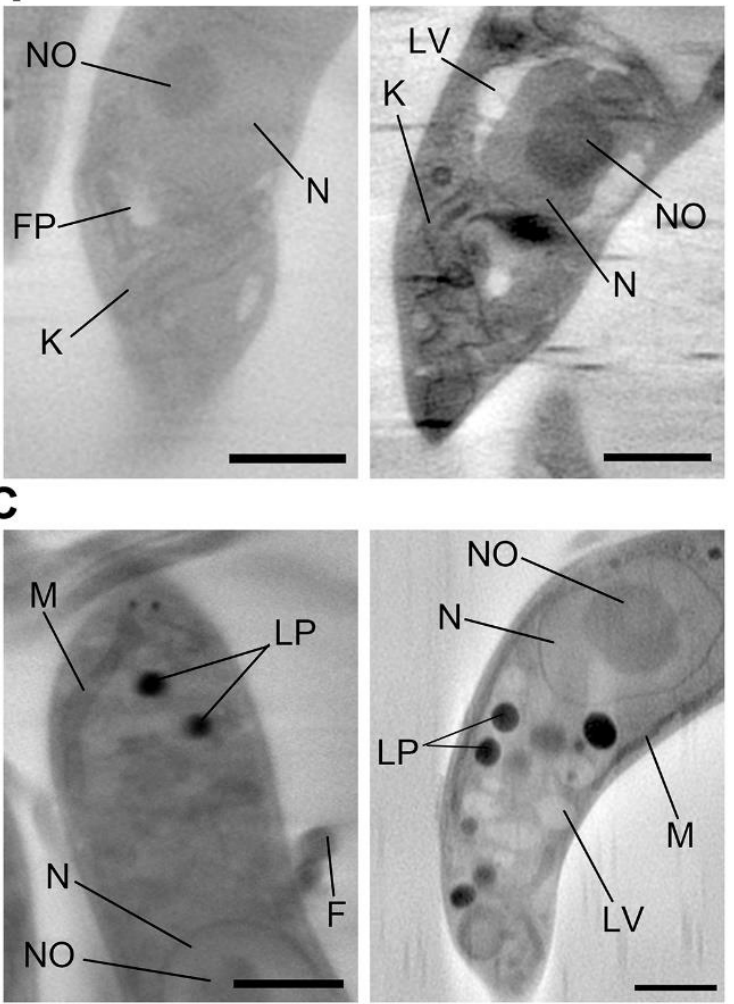

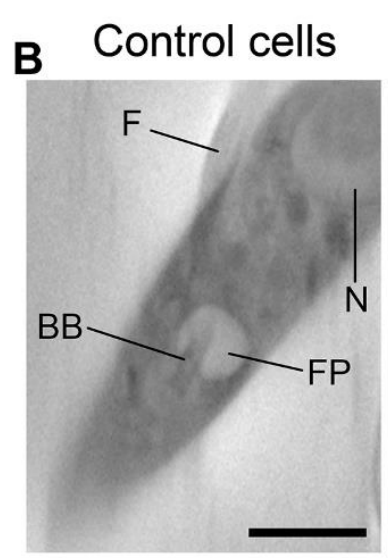

D

Knockdown cells
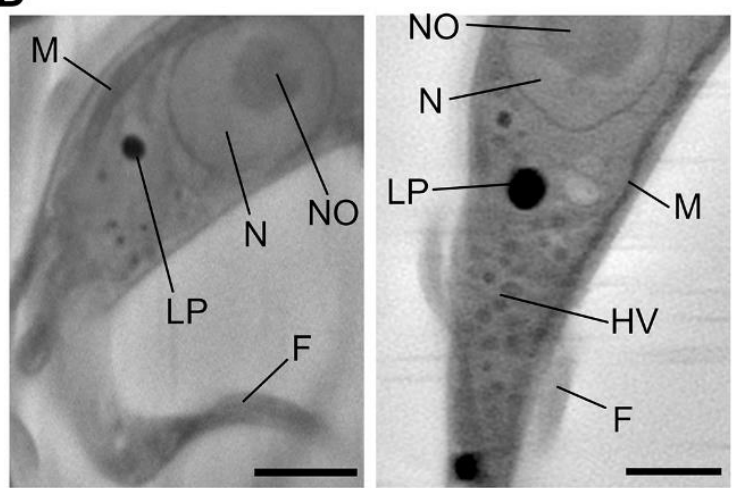

S5 Fig. Cryo-SXT comparison between control and TbRrp44 knockdown cells showing different alterations in the anterior and posterior cellular poles. (A, B and C) Volume slices of the anterior pole showing that the kinetoplast remains intact in knockdown cells and a smaller and/or deformed flagellar pocket in comparison with the controls. (D) Volume slices of the posterior pole. Differences between control and knockdown cells include nuclei with different shapes, vacuoles around the nucleus, increase of the number of vesicles such as lipid droplets, high absorption vesicles and low absorption vesicles. Letters indicate the organelles identified. N: nucleus; NO: nucleolus; K: kinetoplast; F: flagellum; M: mitochondrion; HV: high absorption vesicles; LV: low absorption vesicles; BB: basal body; A: acidocalcisomes; LP: lipid droplet. Scale bar, $1.5 \mu \mathrm{m}$. 